\title{
Atherosclerosis as an Inflammatory Disease
}

\author{
Antonino Tuttolomondo ${ }^{1 *}$, Domenico Di Raimondo ${ }^{1}$, Rosaria Pecoraro ${ }^{1}$, Valentina $\mathrm{Arnao}^{2}$, Antonio Pinto ${ }^{1}$ \\ and Giuseppe Licata ${ }^{1}$
}

\author{
${ }^{1}$ Dipartimento Biomedico di Medicina Interna e Specialistica Università degli Studi di Palermo, Italy; ${ }^{2}$ Dipartimento di Biopatologia \\ e Neuroscienze Cliniche, Università degli Studi di Palermo, Italy
}

\begin{abstract}
In many ways, atherosclerosis is a chronic inflammatory disorder and this issue is confirmed by recent investigations of that have focused on inflammation, providing new insight into mechanisms of disease. Several recent studies have addressed the role of chemokines in leukocyte accumulation in atherosclerosis, extending our knowledge and understanding of the complex and cell typespecific functions of chemokines in atherosclerosis. Activated T-lymphocytes within the atherosclerotic vessel wall express the CD40 ligand surface molecule, known to play a major role in several immunological pathways. In addition to activated T-lymphocytes, functional CD40 and CD40L are coexpressed by human vascular endothelial cells, smooth muscle cells and human macrophages in vitro as well as in situ in human atherosclerotic lesions. Recent studies indicate that CD40L activates atheroma-associated cells by promoting the expression of molecules thought to be involved in atherosclerosis, such as adhesion molecules, cytokines, matrix metalloproteinases, and tissue factor. Atherosclerosis starts with an innate immune response involving the recruitment and activation of monocytes macrophages that respond to an excessive accumulation of modified lipids within the arterial wall, followed by an adaptive immune response involving antigen-specific $\mathrm{T}$ lymphocytes. Effector $\mathrm{T}$ cells recognize modified auto-antigens such as oxidized LDL and heat shock proteins (i.e. HSP-60) that are presented by antigen-presenting cells such as macrophages or dendritic cells. The accumulation of inflammatory cells within the arterial wall leads to local production of chemokines, interleukins and proteases that enhance the influx of monocytes and lymphocytes, thereby promoting the progression of atherosclerotic lesions Recent reports have helped explain some of these questions by pointing to a role of contact dependent interaction between CD40 and CD40 ligand (CD40L, renamed CD154) as a stimulus for atheroma-associated cells. Also Macrophages play important roles in the progression of atherosclerosis by exhibiting unique characteristics under the various stimuli, evolving the plaque instability, thrombus formation and remodeling. Macrophage recruitment by abnormal endothelium over developing atherosclerotic plaques, is aided by endothelial expression of adhesion molecules (ICAM-1, VCAM, ELAM). The knowledge of atherosclerosis as an inflammatory disease offers the opportunity to develop novel therapeutic strategies targeting the inflammatory component of the disease.
\end{abstract}

Keywords: Atherosclerosis, inflammation, cytokines.

\section{INTRODUCTION}

Atherosclerosis is a process of progressive thickening and hardening of the walls of medium-sized and large arteries as a result of fat deposits on their inner lining. It is a pathological condition that underlies several important adverse vascular events including coronary artery disease (CAD), stroke, and peripheral arterial disease, responsible for most of the cardiovascular morbidity and mortality in the Western world today. In many ways, atherosclerosis is a chronic inflammatory disorder and this issue is confirmed by recent investigations of that have focused on inflammation, providing new insight into mechanisms of disease [1-4].

The lesions of atherosclerosis occur principally in large and medium-sized elastic and muscular arteries and can lead to ischemia of the heart, brain, or extremities, resulting in infarction.

The concept of the involvement of inflammation in atherosclerosis has spurred the discovery and adoption of inflammatory biomarkers for cardiovascular risk prediction. C-reactive protein is currently the best validated inflammatory biomarker; in addition, soluble CD40 ligand, adiponectin, interleukin 18, and matrix metalloproteinase 9 may provide additional information for cardiovascular risk stratification and prediction. This trend of new definitions of atherosclerosis appeared in the mid 1970s, when Russel Ross developed his popular "response to injury" hypothesis of atherogenesis, postulating that atherosclerotic lesions arise as a result of focal injury to the arterial endothelium, followed by adherence and aggregation of platelets [5] More recently a review by Ross [6] described recent advances understanding of the cellular composition of the lesions of atherosclerosis and has emphasized the interactions

*Address correspondence to this author at the Dipartimento Biomedico di Medicina Interna e Specialistica Università degli Studi di Palermo, Italy; Tel: +39-091 655 2128; Fax: +39-091 6552285 ;

E-mail: bruno.tuttolomondo@unipa.it among the cells involved in lesion formation during hypercholesterolemia reporting the involvement of inflammatory cells such as leukocytes and macrophages.

The earliest type of lesion, the so-called fatty streak is a pure inflammatory lesion, consisting only of monocyte-derived macrophages and T lymphocytes $[7,8]$.

Substantial evidence has been accumulated to establish the notion that atherosclerosis is an inflammatory disease. The continuous immigration and infiltration of activated macrophages and $\mathrm{T}$ cells into and within atherosclerotic lesions are prominent features in both human and experimental atherosclerotic disease. The recruitment of these cells to lesions is guided by endothelial leukocyte adhesion molecules and chemoattractants. In keeping with this formulation, the atherosclerotic plaque has as its major components macrophages, cells of the adaptive immune system, smooth muscle cells, and matrix components. As with most chronic inflammatory reactions, the cells of the immune system have the potential to significantly influence the outcome of the inflammation.

The atherosclerotic plaque is notable for its focal nature, being mostly encountered in regions of the macrovasculature subject to disturbed flow hemodynamics.

On this basis it's possible to define atherosclerosis as a chronic inflammatory disease of the arterial wall where both innate and adaptive immune responses contribute to disease initiation and progression. Atherosclerotic lesions are characterized by the infiltration of immune competent cells such as macrophages and $\mathrm{T}$ lymphocytes, the proliferation of intimal cells of the arterial wall, the accumulation of lipids and the deposition of extracellular matrix components [see Fig. (1)]. For some years, endothelial cells, smooth muscle cells, and macrophages have been accorded crucial roles in the process of atherosclerosis. The mechanisms by which these cells contribute to atherosclerosis include augmented expres- 

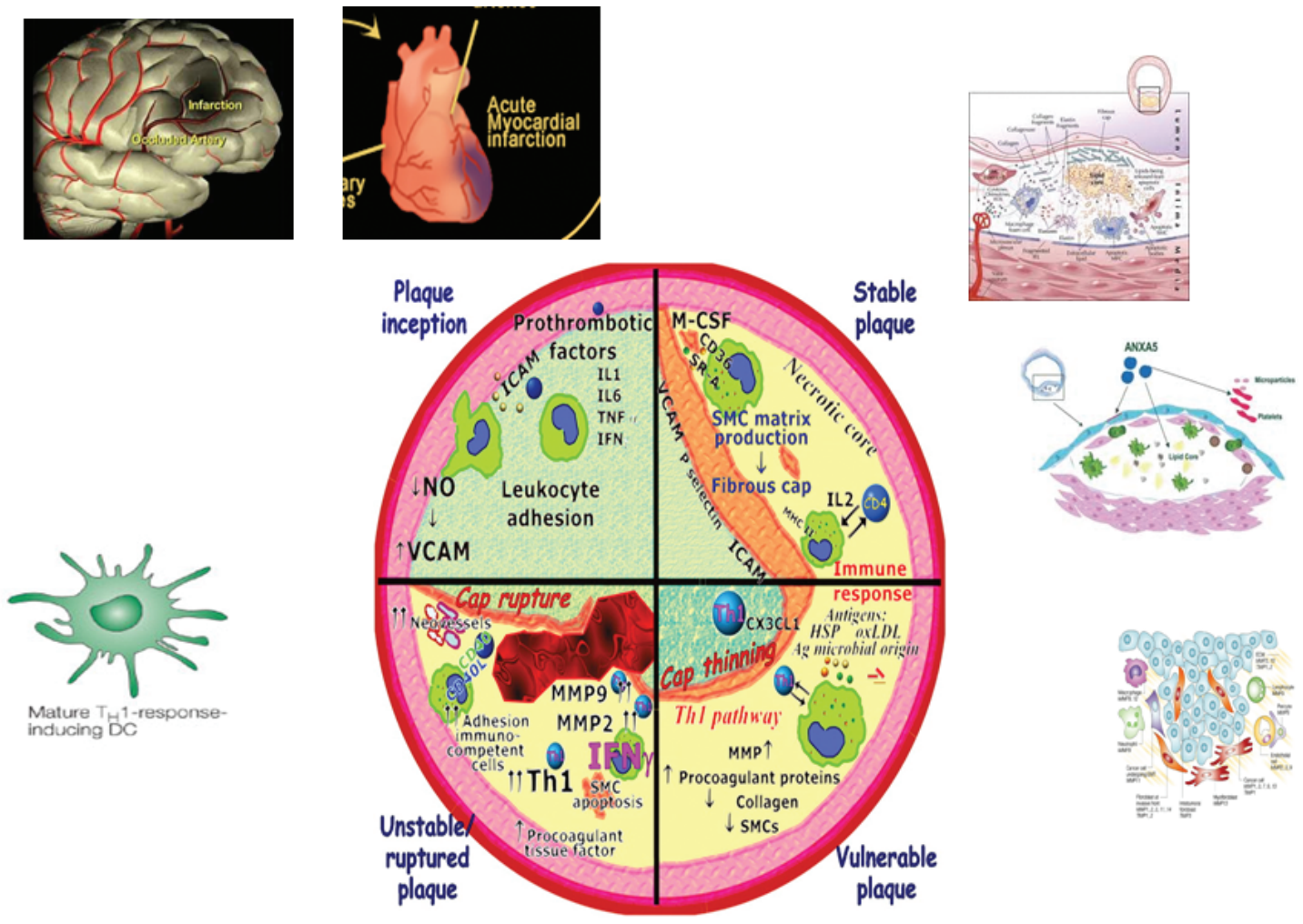

Modified from Spagnoli LG et alJ Nucl Med 2007; 48 (11):1800-1815

Fig. (1). Inflammatory events in plaque progression.

sion of adhesion molecules, as well as secretion of proinflammatory cytokines, matrix metalloproteinases, and tissue factor within human and experimental atheroma [see Fig. (2)]. Much evidence supports the role of tissue factor in inciting the thrombosis that causes most acute coronary syndromes. Macrophage content and expression of tissue factor correlate with rupture and instability of the atherosclerotic plaque [see Fig. (3)]. Matrix metalloproteinases can digest the plaque's extracellular matrix, and thus impair its stability. Plaque rupture exposes circulating blood components to the tissue factor-rich lipid-core, inciting thrombosis. Despite the increasing appreciation that atherogenesis involves participation of inflammatory pathways within cellular interactions, mediators of local communication between the major cell types within atherosclerotic plaques remain incompletely defined. By early appearance, activated T-cells may act as the orchestrator of atherogenesis. Both soluble and contact-dependent mediators from T-cells may be crucial in the development of this prevalent disease.

\section{Role of Chemokines and Cytokines}

Several recent studies have addressed the role of chemokines in leukocyte accumulation in atherosclerosis, extending our knowledge and understanding of the complex and cell type-specific functions of chemokines in atherosclerosis. Chemokines belong to a large group of structurally related and secretable, largely basic, chemotactic cytokines, which can be divided into 4 families $(\mathrm{CC}$, $\mathrm{CXC}, \mathrm{CX} 3 \mathrm{C}, \mathrm{XC}$ ) based on the position of the first 2 cysteine residues. Chemokines can be located in different vascular cell types, eg, endothelial cells (ECs) but also inflammatory cells and can be detected within atherosclerotic lesions, where they function as messengers to direct leukocytes to sites of inflammation but may also control homeostasis and other activities of emigrated cells $[8,9]$.

The expression of CCL5 can be detected in atherosclerotic plaques and in monocyte/macrophages is regulated by the Rel pro- teins p50 and p65 belonging to the NF-KB family. In addition, the Krüppel-like factor 13 (KLF13), originally designated RANTES factor of late activated T lymphocytes-1 (RFLAT-1), has been identified as a new transcription factor regulating the expression of CCL5 in T lymphocytes $[9,10]$. In smooth muscle cells (SMCs), the expression of CCL5 has recently been found to be controlled by the transcriptional regulator Y-box binding protein-1 (YB-1) [11]. The overexpression of YB-1 in arterial SMCs enhanced CCL5 transcriptional activity, CCL5 mRNA and protein expression, and CCL5mediated monocyte recruitment. The expression of chemokines in inflamed plaque areas is related to different shear stress conditions. Whereas low shear stress increases lipid and matrix metalloproteinase (MMP) but decreased vascular SMC and collagen content contributing to atherosclerosis in mice, vortices with oscillatory shear stress induced more stable lesions (Cheng C, Tempel D, van Haperen R, van der Baan A, Grosveld F, Daemen MJ, Krams R, de Crom R. Atherosclerotic lesion size and vulnerability are determined by patterns of fluid shear stress. Circulation 2006; 113: 2744-2753). Whereas the expression of CX3CL1 was found in low shear stress regions only,blockade of CX3CL1 inhibited plaque growth and resulted in striking differences in plaque composition in low shear stress regions of carotid arteries [12]. In the presence of high-shear stress, firm adhesion of leukocytes to inflamed ECs was reduced by blocking antibodies directed against CX3CL1 or CX3CR1 in Apoe / mice, suggesting that this axis is critically involved in leukocyte adhesion to inflamed arterial endothelium. Platelets were required for CX3CL1-induced leukocyte adhesion at high-shear rates and both soluble and membrane-bound CX3CL1 can induce platelet degranulation and subsequent surface expression of P-selectin to promote direct platelet-leukocyte interactions [13 ].

Lymphotoxin $\alpha$ functions as a proinflammatory cytokine in murine atherosclerosis [14]. Either the absence of IL-1 or a reduced gene dosage of IL-1 receptor antagonist in the apoE-deficient back- 



Fig. (2). Inflammatory cells in atherosclerosis.

ground suggests an influence of IL-1 in promoting atherogenic cell signaling $[15,16]$. The larger lesions of the IL-1 receptor antagonistdeficient mice are eriche in macrophages relative to smooth muscle cells. The knockout of IFN- $\gamma$ in the LDL receptor-deficient background substantially reduced lesion size in several regions of the aorta, with a relative loss of macrophages and smooth muscle cells in the early lesions [17].

Nowadays, the cytokines consist of more than 50 secreted factors involved in intercellular communication, which regulate fundamental biological processes including body growth, lactation, adiposity, and hematopoiesis [18]. Cytokines are clustered into several classes: interleukins [19] have been identified to date), tumor necrosis factors (TNF), interferons (IFN), colony stimulating factors (CSF), transforming growth factors (TGF), and chemokines. They are especially important for regulating inflammatory and immune responses and have crucial functions in controlling both innate and adaptive immunity. The predominant actors in adaptive immunity, helper-T (Th) cells, have been categorized on the basis of the pattern of cytokines that they can secrete, resulting in either a cell-mediated immune response (Th1) associated with IL-2 and IFN- $\gamma$ secretion, or a humoral immune response (Th2), associated with IL-4, IL-5, IL-10, and IL-13 secretion.

According to the classical view of inflammation, cytokines are produced by cells of the innate immune system (monocytes, neutrophils, NKT cells) in response to microbial infection, toxic reagents, trauma, antibodies, or immune complexes [20]. In the host, TLRs and intracellular proteins (NOD1 and NOD2, for "nucleotidebinding oligomerization domain") act as sensors of the conserved molecular motifs present on a wide range of different microbes, the PAMPs. Hence, cytokines are secondary mediators of inflammation and not the primary triggers. Once inflammation has been triggered and cytokine release is initiated at the onset of atherosclerotic lesion development, a number of factors that are found in the atherosclerotic plaque can participate in maintaining and amplifying cytokine production. Animal models of atherosclerosis have shown a very early role for HSP60 in the development of the disease. Besides their role as autoantigens, HSPs can act as an amplifier of the cytokine production. Although HSPs are typically regarded as intracellular proteins, HSP60 and HSP70 are present in the sera of clinically normal individuals [21,22] and enhanced levels of circulating HSP60 are associated with early atherosclerosis in clinically normal subjects as well as with peripheral vascular disease [23]. while TNF- $\alpha$ may help in perpetuating sustained levels of proinflammatory cytokines, it does not appear to be a prerequisite for their induction in atherosclerosis. Even though the expression of proinflammatory cytokines is significantly decreased in apoE_ _ mice deficient in TNF- $\alpha$ compared with apoE_/_ mice, it is not totally abolished. Of importance, the immunoinflammatory pathway related to CD40 and its ligand (CD40L) mediates proatherogenic biological responses, such as the expression of cytokines, chemokines, growth factors, matrix metalloproteinases, and procoagulants on EC, SMC, and macrophages,suggesting a major role in atherosclerosis.

The first evidence that cytokines are expressed in the atherosclerotic plaque stems from the observation in the mid 1980s by Hansson and co-workers [24] that most of the cells present in the plaque express the MHC class II antigen HLA-DR, indicating that IFN- $\gamma$ must be produced in the vicinity of these cells. This was demonstrated later on by the same group [25,26] determined the expression profiling of Th1 and Th2 cytokines in advanced human atherosclerotic plaques. They found that IL-2 was present in $50 \%$ of 


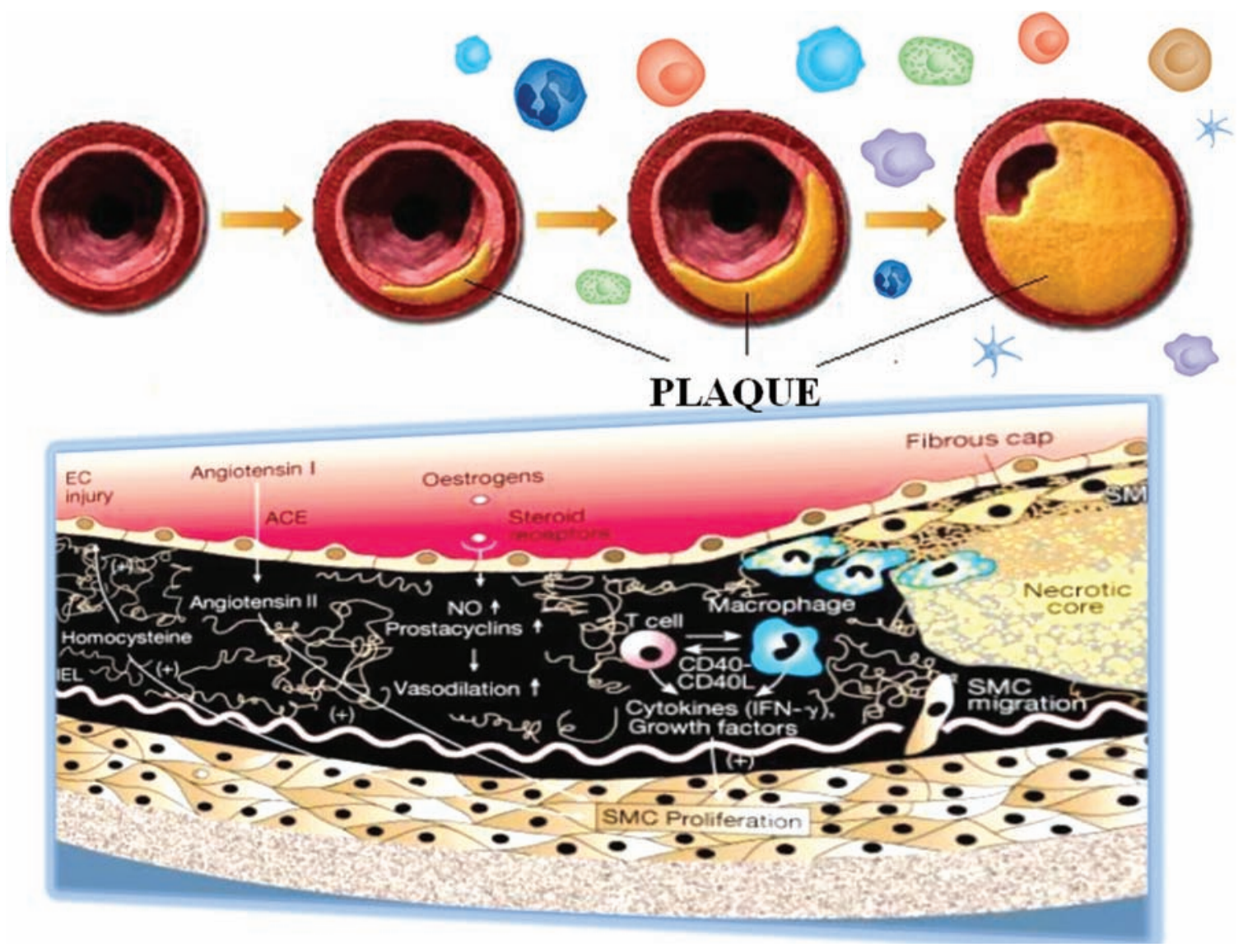

Fig. (3). Inflammatory pathways involved in atherosclerotic plaque progression.

plaques, and IFN- $\gamma$ was detected in some but not all of the IL-2positive plaques. In contrast, the expression of IL-4 and IL-5, Th2 cytokines, and TNF- $\alpha$ (lymphotoxin- $\alpha$ ), expressed by both Th1 and Th2 cells, was very scarce, and IL-10 was not detected at all. Subsequent experiments in murine models [26,28] and TGF- $\alpha$ [29-34] in this setting led to the conclusion that the balance between proinflammatory and anti-inflammatory cytokines is decisive for disease development and progression.

The majority of cytokines stimulates immune cell proliferation and differentiation. This group includes IL-1, which activates $\mathrm{T}$ cells; IL-2, which stimulates proliferation of antigen-activated $\mathrm{T}$ and B cells; IL-4, IL-5, and IL-6, which stimulate proliferation and differentiation of B cells; IFN $\gamma$, which activates macrophages; and IL-3, IL-7 and GM-CSF, which stimulate hematopoiesis. Cytokines could induce vascular cell growth and migration. Both TNF- $\alpha$ and IL-6 induce VEGF expression in cultured A431 human epithelial carcinoma, and L8 rat skeletal myoblast cell lines [35] IL-1 promotes the growth of rat aorta VSMC via induction of endogenous PDGF production, a process that may participate in the abnormal proliferation of VSMC that occurs early in atherogenesis [36]. Also, IL-1, and inflammatory exudate from zymosan-activated air pouches stimulate chemotaxis of SMCs in an extracellular Ca2+dependent fashion. These observations suggested that chempattarctants from inflammatory cells such as macrophages and polymorphonuclear leukocytes play a role in the migration of SMC into the intima during atherogenesis, and that $\mathrm{Ca} 2+$ antagonists might be useful in reducing SMC migration and in treatment of atherosclerosis [37].
Other cytokines such as TNF- $\alpha$ may induce apoptosis. TNF- $\alpha$ initiates apoptosis in many cell types by the recruitment of the DED containing protein caspase- 8 to the receptor complex following association of TRADD and FADD to TNFR-1. This receptor recruitment results in autocatalytic activation of caspase- 8 . Once autocatalytically processed, activated caspase- 8 initiates a hierarchical series of caspase activation steps culminating in the activation of effector caspases such as caspase-3 [38]. In EC, transfection of the viral caspase- 8 inhibitor CrmA inhibits TNF-induced apoptosis, suggesting that EC activation of caspase- 3 involves upstream activation of caspase-8 [39].

Cytokines also promote adhesion of immune cells to ECs and cause an increase in vascular permeability. Studies have examined the effects of TNF- $\alpha$ on the expression of transient receptor potential channel (TRPC) homologues in human vascular ECs and the consequences of TRPC expression on EC permeability. It was found that TNF- $\alpha$ exposure increased TRPC1 expression in human pulmonary artery endothelial cells (HPAEC). Also, thrombininduced $\mathrm{Ca} 2+$ influx was twofold greater in $\mathrm{TNF}-\alpha$-stimulated HPAEC than in control cells. When TRPC1 was overexpressed in human dermal microvascular endothelial cell line (HMEC) using TRPC 1 cDNA, thrombin-induced depletion of $\mathrm{Ca} 2+$ stores in these cells caused twofold greater in TNF- $\alpha$-stimulated HPAEC than in control cells.

These findings indicate that TNF- $\alpha$ induced expression of TRPC1 in ECs is a critical determinant of $\mathrm{Ca} 2+$ influx and signaling of increased EC permeability [40].

The various risk factors, represented by particular compounds (activators), may cause altered cellular functions in the endothelium 
(e.g. EC-activation or -dysfunction), in invading cells (e.g. inflammatory mediator production) or in local vessel wall cells (e.g. inflammatory mediators, migration), thereby triggering the innate inflammatory process. The cellular components of innate immunology include granulocytes, NK-cells and monocytes. Among the molecular innate constituentsare innate molecules, such as the tolllike receptors or innate cytokines. Interleukin-1 (IL-1) and IL-6 are among the innate cytokines. Cytokines are potent activators of a great number of cellular functions relevant to maintain or commove homeostasis of the vessel wall. Within the vessel wall, smooth muscle cells can significantly contribute to the cytokine-dependent inflammatory network by: a) production of cytokines, b) response to cytokines and c) cytokine-mediated interaction with invading leukocytes. The cytokines IL-1 and IL-6 are involved in SMCleukocyteinteraction. The IL-6 effects are proposed to be mediated by trans-signalling. Dysregulated cellular functions resulting from dysregulated cytokine production may be the cause of cell accumulation, subsequent LDL accumulation and deposition of extracellular matrix (ECM). The deposition of ECM, increased accumulation of leukocytes and altered levels of inflammatory mediators wall may constitute an "innate-immunovascular-memory" resulting in an ever-growing response to anew invasion. Thus, vascular smooth muscle cell-fostered inflammation, promoted by invading innate cells, may be a potent component for development and acceleration of atherosclerosis. Plasma levels of cytokines and related proteins, such as CRP, have been investigated in cardiovascular patients, tissue mRNA expression was analyzed and correlations to vascular diseases established. Consistent with these findings the generation of cytokine-deficient animals has provided direct evidence for a role of cytokines in atherosclerosis. In vitro cell culture experiments further support the suggestion that cytokines and other innate mechanisms contribute to atherogenesis. Among the initiation pathways of atherogenesis are innate mechanisms, such as toll-likereceptors (TLRs), including the endotoxin receptor TLR4. On the other hand, innate cytokines, such as IL-1 or TNF, or even autoimmune triggers may activate the cells. Cytokines potently activate multiple functions relevant to maintain or spoil homeostasis within the vessel wall. Vascular cells, not least smooth muscle cells, can actively contribute to the inflammatory cytokine-dependent network in the blood vessel wall by: (i) production of cytokines; (ii) response to these potent cell activators; and (iii) cytokine-mediated interaction with invading cells, such as monocytes, T-cells, or mast cells. Activation of these pathways results in accumulation of cells and increased LDL- and ECM-deposition which may serve as an 'immunovascular memory' resulting in an ever-growing response to subsequent invasions. Thus, vascular cells may potently contribute to the inflammatory pathways involved in development and acceleration of atherosclerosis.

Nevertheless the signalling mechanisms via which cytokines could affect vascular function and vascular disease need to be further examined. Such studies would provide the basis for the use of inflammatory cytokines in the diagnosis of vascular disease.

\section{Role of CD40 and CD40-L}

Recent reports [41] have helped explain some of these questions by pointing to a role of contact dependent interaction between CD40 and CD40 ligand (CD40L, renamed CD154) as a stimulus for atheroma-associated cells. Activated T-lymphocytes within the atherosclerotic vessel wall express the CD40 ligand surface molecule, known to play a major role in several immunological pathways. In addition to activated T-lymphocytes, functional CD40 and CD40L are coexpressed by human vascular endothelial cells, smooth muscle cells and human macrophages in vitro as well as in situ in human atherosclerotic lesions. Recent studies indicate that CD40L activates atheroma-associated cells by promoting the expression of molecules thought to be involved in atherosclerosis, such as adhesion molecules, cytokines, matrix metalloproteinases, and tissue factor. Thus, CD40 ligation on these vascular wall cells may promote mononuclear cell recruitment, participate in the weakening of the plaque and set the stage for thrombosis, mechanisms of crucial importance in the process of atherosclerosis. The involvement of the CD40 signaling pathway may play major roles during atherogenesis by regulating antigen-specific $\mathrm{T}$-cell responses to yield activation instead of tolerance, and the presence of functional CD40L on non-leukocytic cells associated with atherosclerotic lesion indicates a novel T-cell-independent route of inflammatory activation, a now well recognized component of atherogenesis. These findings establish a possible crucial role for CD40-CD40L interactions in a prevalent human disease.

In accordance with the hypothesis that CD40 signaling promotes plaque instability, in vitro studies demonstrated that ligation of CD40 on atheroma-associated cell types, namely endothelial cells, smooth muscle cells, and macrophages, mediates functions considered crucial to the process of atherogenesis, such as the expression of cytokines, chemokines, growth factors, matrix metalloproteinases, and procoagulants. The combination of the broad gamut of proatherogenic biological responses triggered by ligation of CD40 on endothelial cells, smooth muscle cells, and macrophages in vitro and the results of in vivo studies of interruption of CD40 signaling suggests a central role for this receptor/ligand dyad during atherogenesis, proposing $\mathrm{CD} 40 / \mathrm{CD} 40 \mathrm{~L}$ interactions as a novel potential therapeutic target for this prevalent human disease.

CD40 is a cell membrane-spanning protein of ' $50 \mathrm{kDa}$ that was found originally on B lymphocytes.

It is responsible for B lymphocyte activation and serves several key functions. Engagement of B lymphocyte CD40 by its ligand (commonly called CD40L but officially termed CD154) helps prevent induction of apoptosis, induces expression of key costimulatory molecules such as B7 for interaction with T lymphocytes, and is crucial for B lymphocytes to undergo Ig class switching. The display of CD40L on T lymphocytes permits a mutual amplification scheme. Key antigen-presenting cells, including macrophages and dendritic cells that can activate $\mathrm{T}$ lymphocytes, also expressed CD40. Engagement of CD40 by T lymphocyte CD40L also served to activate these cells to express different functions, such as the production of the type 1 cytokines IL-1, IL-12, and tumor necrosis factor-a [42]. Interestingly, further analyses showed that nonhematopoietic cells including fibroblasts, endothelial cells, smooth muscle cells, and certain epithelial cells expressed CD40 and that its display could be markedly up-regulated after exposure to IFN- $\gamma$ [43-47]. Moreover, CD40 engagement on fibroblasts and endothelial cells induces synthesis of cyclooxygenase- 2 and resultant production of prostaglandins.

CD40-CD40L pathway is a key element in atherosclerosis. Endothelial cells, macrophages, and smooth muscle cells from human atheroma all express high levels of CD40 [48]. Moreover, these cells can be activated in vitro with recombinant forms of CD40L or with $\mathrm{T}$ lymphocyte membranes displaying CD40L to express characteristics important in atherosclerosis.

These include dramatic up-regulation of connective tissuedegrading MMP [49]. MMP production induced by CD40 could destabilize the fibrous plaque cap and allow rupture with obvious consequences. Moreover, studies showed, in two different model systems, one with CD40L2y2yApoE2y2 mice and the other with an anti-CD40L antibody treatment of low-density lipoprotein receptordeficient mice, that initial plaque lesions were smaller and were of a more stable composition [49]. A study in humans has shown recently that patients with unstable angina have particularly high blood levels of soluble and membranebound forms of CD40L [50]. These observations suggest that chronic provocation by CD40L and activation of CD40- L bearing cells, especially in the plaque microenvironment, could lead to plaque destabilization and rupture.

The interaction of CD40 with CD40L figures prominently in both humoral and cell-mediated immune responses. CD40L- 
positive $\mathrm{T}$ cells accumulate in atheroma, and, by virtue of their early appearance, persistence and localization at sites of lesion growth and complication, activated $\mathrm{T}$ cells may coordinate important aspects of atherogenesis. Interruption of CD40L-CD40 signalling by administration of an anti-CD40L antibody limits experimental autoimmune diseases such as collagen-induced arthritis, lupus nephritis, acute or chronic graft-versus-host disease, multiple sclerosis and thyroiditis. Ligation of CD40 on atheroma-associated cells in vitro activates functions related to atherogenesis, including induction of proinflammatory cytokines, matrix metalloproteinases, adhesion molecules and tissue factor. However, the role of CD40 signalling in atherogenesis in vivo remains unknown. Shonbeck et al. [51] reported that anti-CD40L antibody treatment of randomly assigned low-density lipoprotein receptor-deficient mice during the second half of a 26-week regimen of high-cholesterol diet did not regress, but did significantly reduce further evolution of established atherosclerotic lesions within the aortic arch and particularly the thoracic and abdominal aorta, as compared with control treatment (application of rat-IgG or saline; 13 weeks, continued highcholesterol diet). In addition to limiting lesion progression, antiCD40L treatment changed the composition of atheroma in manners thought to favor plaque stability, e.g, reduced relative content of macrophages and lipid, as well as increased relative content of smooth muscle cells and collagen. These data implicate CD40/CD40L as crucial mediators not only in the initial events of atherogenesis but also during the evolution of established atheroma.

Mach et al. [52] determined whether interruption of CD40 signalling influences atherogenesis in vivo in hyperlipidaemic mice. Treatment with antibody against mouse CD40L limited atherosclerosis in mice lacking the receptor for low-density lipoprotein that had been fed a high-cholesterol diet for 12 weeks. This antibody reduces the size of aortic atherosclerotic lesions by $59 \%$ and their lipid content by $79 \%$. Furthermore, atheroma of mice treated with anti-CD40L antibody contained significantly fewer macrophages (64\%) and $\mathrm{T}$ lymphocytes $(70 \%)$, and exhibited decreased expression of vascular cell adhesion molecule- 1 . These data support the involvement of inflammatory pathways in atherosclerosis and indicate a role for CD40 signalling during atherogenesis in hyperlipidaemic mice.

\section{Role of $\mathbf{T}$ and B Cells}

Atherosclerosis starts with an innate immune response involving the recruitment and activation of monocytes macrophages that respond to an excessive accumulation of modified lipids within the arterial wall, followed by an adaptive immune response involving antigen-specific $\mathrm{T}$ lymphocytes. Effector $\mathrm{T}$ cells recognize modified auto-antigens such as oxidized LDL and heat shock proteins (i.e. HSP-60) that are presented by antigen-presenting cells such as macrophages or dendritic cells [53]. The accumulation of inflammatory cells within the arterial wall leads to local production of chemokines, interleukins and proteases that enhance the influx of monocytes and lymphocytes, thereby promoting the progression of atherosclerotic lesions [54]. T-cells may be divided into CD4 + and CD8+ subclasses.

The majority of T-cells in atherosclerotic plaques are CD4+ cells, although smaller numbers of CD8+ cells have been detected. $\mathrm{CD} 4+$ cells recognize antigen loaded on MHC class II molecules of the antigen-presenting cell, whereas $\mathrm{CD} 8+$ cells recognize antigens presented in the context of MHC class I molecules. Among the CD4+ cells are several subgroups, three of which have been investigated in murine atherosclerosis. These subgroups are distinguished by the complement of cytokines they produce. Th1 cells mainly secrete proinflammatory cytokines such as IFN- $\gamma$ which activates macrophages and facilitates the production of antibodies of the IgG2a class by B-cells. T-helper 1 (Th1) cells do not secrete IL-4 or IL-5. Th 2 cells, on the other hand, secrete IL-4 and IL-5 but not IFN- $\gamma$. These cells provide help for the synthesis of other anti- body classes. The Th2 cytokines may be anti-inflammatory. There is cross-regulation among these two subsets of T-cells, so that each tends to inhibit the other. IFN- $\gamma$ inhibits Th2 cells and IL-4 inhibits Th1 cell cytokine secretion. Also,IL-10 inhibits the Th1 pathway, whereas IL-12 reduces the Th2 responses [55]. A third special subset of T-cells are the natural killer T cells (NK-T cells), which bear some of the same markers as NK cells, but unlike the latter they express rearranged cell surface TCRs of limited diversity. They mainly recognize lipid antigen in the context of the MHC-like compound CD1. There are other T-cell subsets that have been less studied in atherosclerosis (e.g, T-regulatory cells, Th3 cells, etc.).

Some authors reported that Th1-driven responses, characterized by c-interferon (IFN-c) production are detrimental to the atherosclerotic process $[56,57]$ The role of the Th2 pathway in the development of atherosclerosis remains controversial depending on the stage and or site of the lesion, as well as on the experimental model [58]

IFN- $\gamma$-producing TH1 CD4+ T-cells with $\alpha \beta$ T-cell receptors constitute the majority of $\mathrm{T}$ lymphocytes present in human 135 and experimental 136 atherosclerotic lesions [59] T-cells enter lesions in response to the chemokines inducible protein-10 (IP-10), monokine induced by IFN- $\gamma$ (MIG), and IFN-inducible T-cell $\alpha$ chemoattractant (I-TAC), which bind CXCR3, highly expressed by $\mathrm{T}$ lymphocytes in the plaque 137. CD4+ T-cells undergo oligoclonal expansion within lesions, suggesting the occurrence of antigen-driven T-cell proliferation 138. Indeed, CD4+ T-cell clones in plaques recognize oxLDL 139 and hsp60 [60]. Experimental evidence supports an important role for CD4+ T-cells in atherosclerosis.

Immunodeficient RAG (recombinase activating gene)-deficient [61] or DNA-PK (DNAdependent protein kinase)-knockout [62] atherosclerosis-prone mice have no lymphocytes and reduced lesions compared to immunocompetent atherosclerosis-prone mice. Adoptive transfer of CD4+ T-cells into immunodeficient animals, however, greatly increases lesion size in parallel to increased T-cell recruitment and MHC-II expression in plaques In mice, decreased Treg numbers 189 or Treg function secondary to absence of ICOS 128 leads to increased lesional CD4+ T cells and macrophage numbers as well as amplified expression of the pro-inflammatory cytokines IFN- $\gamma$ and TNF- $\alpha$. Moreover, patients with acute coronary syndromes have reduced circulating Treg numbers and suppressive function [63]. Conversely, the adoptive transfer of Tregs [64] or Treg-induction secondary to measles virus nucleoprotein vaccination[65] inhibits macrophage and T-cell accumulation within lesions. In addition, leptin deficiency in atherosclerosis-prone mice reduces atherosclerotic lesion formation, in association with diminished Th1 responses in addition to a marked increase in the number and suppressive function of Tregs.

B-cells are the other major group of circulating lymphocytes. They recognize antigen via the B-cell antigen receptor, in which cell surface IgM plays a central role. Like T-cells, B-cells, through these receptors, express unique specificity derived from the rearrangement of immunoglobulin genes, a process that is also RAG dependent. Mature B-cells, designated as plasma cells, secrete specific antibodies. The production of antibodies to protein antigen requires T-cell help. The interaction between T-cells and B-cells is facilitated by CD40 ligand (CD40L) expressed on T-cells and CD40 on B-cells [66].

Stromelysin-3 is an unusual matrix metalloproteinase, being released in the active rather than zymogen form and having a distinct substrate specificity, targeting serine proteinase inhibitors (serpins), which regulate cellular functions involved in atherosclerosis. Schönbeck et al. [67] reported that human atherosclerotic plaques $(\mathrm{n}=7)$ express stromelysin-3 in situ, whereas fatty streaks $(\mathrm{n}=5)$ and normal arterial specimens $(\mathrm{n}=5)$ contain little or no stromelysin-3. Stromelysin-3 mRNA and protein colocalized with 
endothelial cells, smooth muscle cells, and macrophages within the lesion. In vitro, usual inducers of matrix metalloproteinases such as interleukin-1, interferon-gamma, or tumor necrosis factor alpha did not augment stromelysin-3 in vascular wall cells. However, T cellderived as well as recombinant CD40 ligand (CD40L, CD154), an inflammatory mediator recently localized in atheroma, induced de novo synthesis of stromelysin-3. In addition, stromelysin-3 mRNA and protein colocalized with CD40L and CD40 within atheroma. In accordance with the in situ and in vitro data obtained with human material, interruption of the CD40-CD40L signaling pathway in low density lipoprotein receptor-deficient hyperlipidemic mice substantially decreased expression of the enzyme within atherosclerotic plaques. These observations establish the expression of the unusual matrix metalloproteinase stromelysin-3 in human atherosclerotic lesions and implicate CD40-CD40L signaling in its regulation, thus providing a possible new pathway that triggers complications within atherosclerotic lesions,

Furthermore, Häkkinen T et al. [68] studied the expression profile of CD40-CD40L in different types of human atherosclerotic lesions using double immunostaining techniques with cell typespecific antibodies. Normal human intima did not contain CD40 or CD40L immunoreactivity. From type-II lesions (fatty streaks) to advanced type-VI lesions (complicated plaques), colocalization of CD40 and CD40L was observed in T cells (CD3+ cells), macrophages (CD68+ cells), and smooth muscle cells (HHF35+ cells). No correlation was found between the lesion type and CD40CD40L expression. Positive lesions had dense infiltrations of macrophages and macrophage-derived foam cells together with $\mathrm{T}$ cells. The most intensive immunoreactivity for the CD40 receptor and its ligand CD40L was found in macrophage- and T-cell-rich pockets, where both cell types were in close contact with each other. The majority of macrophages, and especially those of macrophage-derived foam cells, were positive for both CD40 and CD40L. A small subset of the lesion macrophage population (10-20\%) consisted of cells positive only for either CD40 or CD40L, suggesting the presence of a subpopulation of macrophages more active in inflammatory processes than in lipid uptake. Intimal smooth muscle cells in and around the macrophage-rich areas as well as some of the medial smooth muscle cells near the lesions stained positive for CD40 and CD40L. Moderate to faint expression of these proteins was also found in endothelium. In addition, CD40-CD40L immunoreactivity colocalized with epitopes characteristic of oxidized lowdensity lipoprotein, scavenger receptor class A, and CD16 (Fc gammaRIII), thus suggesting the involvement of CD40-CD40L and these pathogenetic mediators in foam cell formation, progression of atherosclerotic lesions, and differentiation of immunologically active subsets of macrophages. These results support the hypothesis that CD40-CD40L interaction is involved in atherogenesis and that it might provide a target for future therapeutic interventions.

Furthermore, In elderly subjects and in patients with chronic inflammatory diseases, there is an increased subset of monocytes with a CD14(+)CD16(+) phenotype, whose origin and functional relevance has not been well characterized. Merino et al. [69] determined whether prolonged survival of human CD14(++)CD16(-) monocytes promotes the emergence of senescent cells, and we analyzed their molecular phenotypic and functional characteristics. We used an in vitro model to prolong the life span of healthy monocytes. We determined cell senescence, intracellular cytokine expression, ability to interact with endothelial cells, and APC activity. CD14(+)CD16(+) monocytes were senescent cells with shortened telomeres $(215 \pm 37$ relative telomere length) versus $\mathrm{CD} 14(++)$ CD16(-) cells $(339 \pm 44$ relative telomere length; $\mathrm{p}<0.05)$ and increased expression of $\beta$-galactosidase $(86.4 \pm 16.4 \%$ versus 10.3 $\pm 7.5 \%$, respectively; $\mathrm{p}=0.002)$. CD14(+)CD16(+) monocytes exhibited features of activated cells that included expression of CD209, release of cytokines in response to low-intensity stimulus, and increased capacity to sustain lymphocyte proliferation. Finally, compared with CD14(++)CD16(-) cells, CD14(+)CD16(+) monocytes showed elevated expression of chemokine receptors and increased adhesion to endothelial cells $(19.6 \pm 8.1 \%$ versus $5.3 \pm$ $4.1 \% ; \mathrm{p}=0.033)$. These data indicated that the senescent CD14(+)CD16(+) monocytes are activated cells, with increased inflammatory activity and ability to interact with endothelial cells. Therefore, accumulation of senescent monocytes may explain, in part, the development of chronic inflammation and atherosclerosis in elderly subjects and in patients with chronic inflammatory diseases.

\section{Role of Monocytes}

Monocytes circulate in the blood, bone marrow and spleen of mice in homeostasis. These cells are short-lived, and do not proliferate in the blood [70] their functions under homeostatic conditions remain unresolved. They might be involved in scavenging dead cells and toxic molecules, and/or have a potential role in the renewal of 'resident' tissue macrophages and DCs. During inflammation, blood monocytes migrate from blood to lymphoid and nonlymphoid tissues in response to tissue-derived signals caused, for example, by infection or tissue damage [71]. They phagocytose other cells and toxic molecules (such as oxidized LDL [oxLDL]), produce inflammatory cytokines, and can differentiate into inflammatory DCs, macrophages or foam cells $[72,73]$.

During the pathogenesis of atherosclerosis, blood monocytes are recruited into intima and subintima [74]. Through their scavenger receptors, these cells can take up oxLDL and other lipids, consequently, it is thought that, when they encounter fatty deposits, they are induced to undergo activation and accumulate in the forming lesion. At an early stage of the process, monocytes differentiate into foam cells to form early plaques, termed fatty streaks, in the intima [75]. Interestingly, this process occurs in atherosclerosisprone areas of the arterial tree, such as artery branches, and is very likely to involve cellular responses to changes in fluid dynamics.

Although monocytes are recruited into the plaque during its growth, they might also emigrate from the plaque, at least under some experimental conditions that are associated with a decrease in plaque size and, consequently, regression of atherosclerosis $[76,77]$. Monocytes might enter lymphatic vessels and then travel to the draining lymph node, or they might migrate across the arterial endothelium towards the artery lumen to directly enter the circulating bloodstream [78].

Monocytes and macrophages were the first inflammatory cells to be associated with atherosclerosis. Gerrity et al. [79] identified monocytes as the main cellular component of atherosclerotic plaques in porcine specimens. Monocytes are already present in fatty streaks, the earliest visible lesion in human and experimental sclerosis [80]. Depletion of monocytes from the circulation using clodronate (dichloromethylene bisphosphonate) was associated with considerably reduced plaque formation in rabbits, suggesting the importance of monocytes in atherosclerosis [81] showed that $\mathrm{CD} 11 \mathrm{~b}+$ cells are critical to atherogenesis, but that, once formed, the plaque mass was not reduced by depleting CD11b+ cells. As $\mathrm{CD} 11 \mathrm{~b}$ is broadly expressed, and because clodronate also kills several macrophages subsets, these experiments do not formally prove the role(s) of monocytes in atherosclerosis. In addition, if different monocyte subsets have opposing functions, depleting all monocytes will not be sufficient to understand their roles.

Activation of monocytes and differentiation into lipid-laden macrophages are fundamental events in the formation of atherosclerotic lesions. Marginalization of monocytes along the endothelium and transmigration into the intimal spaces appears to depend on the local presence of high amounts of oxidized lowdensity lipoprotein cholesterol and are mediated by adhesion molecules (vascular cell adhesion molecule, intercellular adhesion molecule, and selectin) expressed by the endothelium. [82,83]. Previous studies have found elevated levels of circulating adhesion molecules in subjects with 
carotid atherosclerosis $[84,85]$. In a recent community-based study, monocyte count in blood was found to be a better cross-sectional marker of plaque presence than IL-6, high-sensitive C-reactive protein, fibrinogen, and white blood cells [86].

On this basis monocytes and lymphocytes, but not neutrophils, are the main cellular components of the circulation in generating atherosclerotic lesions. Monocyte count may therefore be a better and more specific marker than WCC of the inflammatory activity in atherosclerosis, Microparticles are membrane vesicles with procoagulant and proinflammatory properties released during cell activation or apoptosis. Microparticles from monocytes have been implicated in atherosclerosis and vascular inflammation, but their direct effects on endothelial cells are not completely elucidated. Mastronardi et al. [87] designed a study to dissect the signaling pathways of monocytic microparticles in endothelial cells with respect to both NO pathway and reactive oxygen species. Microparticles were produced by treatment of human monocytic cell line THP-1 with the apoptotic agent VP-16. Human endothelial cells were treated with monocytic microparticles and authors studied their effects on nitrosative and oxidative stresses. Incubation of human endothelial cells with microparticles enhanced the production of NO without affecting superoxide anions generation. Microparticles did not affect endothelial NO synthase expression and its phosphorylation. Interestingly, microparticles decreased caveolin-1 expression and increased its phosphorylation. Inhibition of PI-3kinase or MEK1/2 reversed the effects of microparticles on caveolin-1 expression but not its phosphorylation. Moreover, microparticles increased nitration of several proteins, reflecting peroxynitrite production, which was prevented by blockade of PI-3-kinase pathway. In summary, monocyte microparticles active multiple pathways related to nitrosative stress in endothelial cells including both PI-3-kinase and ERK1/2 in the regulation of caveolin-1 expression. These data underscore the pleiotropic effect of microparticles on endothelial cells and suggest that they probably play a critical role on vascular function.

Circulating monocytes can be divided into functionally distinct subpopulations according to their surface expression of CD14 and CD16. Monocytes with high-level expression of both antigens $(\mathrm{CD} 14(++) \mathrm{CD} 16(+), \mathrm{Mo} 2$ cells) are associated with cardiovascular morbidity and mortality in hemodialysis patients. These cells express angiotensin converting enzyme (ACE) on their surface. They are involved in the association of chronic inflammation and cardiovascular disease in kidney patients. Cardiovascular morbidity results from atherosclerosis (plaque-forming, vessel occluding disease) and arteriosclerosis (loss of arterial dampening function).

In a study by Ulrich et al. [88] 60 chronic hemodialysis patients were screened for atherosclerosis by carotid artery ultrasound, for arteriosclerosis by pulse pressure measurement, and for ACE expression on $\mathrm{Mo} 2$ cells by flow cytometry. Authors reported that ACE expression on Mo2 monocytes was significantly higher in patients with severe compared with those with little or no carotid atherosclerosis. Mo2 ACE correlated with a score to semiquantify atherosclerosis and remained a significant predictor of carotid plaques in multivariate analysis including the other univariately associated variables of age, hemoglobin A1c, and albumin. Mo2 ACE was not related to pulse pressure. On this basis ACE expression on Mo2, although being a known predictor of mortality and cardiovascular disease in end-stage renal disease patients, may act via enhancement of atherosclerosis rather than arteriosclerosis.

Markers of monocyte activation play a critical role in atherosclerosis, but little is known about the genetic influences on cellular levels. Bielinski et al. [89] investigated the influence of genetic variants in monocyte differentiation antigen (CD14), toll-like receptor-4 (TLR4), toll-like receptor-2 (TLR2), and myeloperoxidase (MPO) on monocyte surface receptor levels. The study sample consisted of 1,817 members of a biracial cohort of adults from the Atherosclerosis Risk in Communities Carotid MRI Study. Mono- cyte receptors were measured using flow cytometry on fasting whole blood samples. TLR2 rs1816702 genotype was significantly associated with CD14+/TLR2+ percent of positive cells (\%) and median fluorescence intensity (MFI) in whites but not in blacks $(\mathrm{p}<0.001)$. Specifically, the presence of the minor T-allele was associated with increased receptor levels. In blacks, TLR4 rs5030719 was significantly associated with CD14+/TLR4+ monocytes (MFI) with mean $\pm \mathrm{SE}$ intensities of $16.7 \pm 0.05$ and $16.0 \pm 0.14$ for GG and GT/TT genotypes, respectively $(\mathrm{p}<0.001)$. Variants in TLR2 and TLR4 were associated with monocyte receptor levels of TLR2 and TLR4, respectively, in a biracial cohort of adults. This is the first study to look at associations between variants in the toll-like receptor family and toll-like receptor levels on monocytes. Patients with systemic lupus erythematosus (SLE) have a high risk of developing cardiovascular disease; however, the mechanisms involved in the early onset of atherosclerosis in these patients are not clear. Scavenger receptors, CD36 and CD163 are expressed by mononuclear phagocytes and participate in the binding and uptake of oxidized low-density lipoproteins (Ox-LDL), contributing to foam-cells formation and atherosclerosis development. Recently some authors [90] evaluated CD36(+) and CD163(+) expression and Ox-LDL removal by monocytes from SLE and atherosclerotic patients, compared to similar age-range healthy controls. Healthy controls, SLE, and atherosclerotic patients were evaluated for carotid intima media thickness (CIMT), lipid profile, and native LDL (N-LDL) and Ox-LDL binding/endocytosis. SLE patients presented decreased high-density lipoproteins (HDL) and increased Triglyceride levels, and half of the SLE patients had increased CIMT, compared to their healthy controls (HC(SLE)). The number of CD14(+)CD163(+) cells was increased in atherosclerosis healthy controls (HC(Atheros)) compared to HC(SLE), but there were no differences between SLE or atherosclerotic patients and their respective healthy controls. Clearance assays revealed a similar capacity to bind/endocytose Ox-LDL by monocytes from SLE patients and HC(SLE), and an increased binding and endocytosis of Ox-LDL by monocytes from atherosclerotic patients, compared to HC(Atheros). The decreased CD36 and CD163 expression observed in atherosclerotic and SLE patients, respectively, suggest that these inflammatory conditions modulate these receptors differentially. The increased CIMT observed in SLE patients cannot be explained by Ox-LDL binding/endocytosis, which was comparable to their controls.

Membrane-shed submicron microparticles (MPs) released following cell activation or apoptosis accumulate in atherosclerotic plaques, where they stimulate endothelial proliferation and neovessel formation. A study by Rautou et al. [91] was to assess whether or not MPs isolated from human atherosclerotic plaques contribute to increased endothelial adhesion molecules expression and monocyte recruitment. Human umbilical vein and coronary artery endothelial cells were exposed to MPs isolated from endarterectomy specimens $(n=62)$ and characterized by externalized phosphatidylserine. Endothelial exposure to plaque, but not circulating, MPs increased ICAM-1 levels in a concentration-dependant manner (3.4-fold increase) without affecting ICAM-1 mRNA levels. Plaque MPs harbored ICAM-1 and transferred this adhesion molecule to endothelial cell membrane in a phosphatidylserine-dependent manner. MP-borne ICAM-1 was functionally integrated into cell membrane as demonstrated by the increased ERK $1 / 2$ phosphorylation following ICAM-1 ligation. Plaque MPs stimulated endothelial monocyte adhesion both in culture and in isolated perfused mouse carotid. This effect was also observed under flow condition and was prevented by anti-LFA-1 and anti-ICAM-1 neutralizing antibodies. MPs isolated from symptomatic plaques were more potent in stimulating monocyte adhesion than MPs from asymptomatic patients. Plaque MPs did not affect the release of interleukin-6, interleukin-8, or MCP-1, nor the expression of VCAM-1 and E-selectin. Results of this study demonstrate that MPs isolated from human atherosclerotic plaques transfer ICAM-1 to endothelial cells to recruit in- 
flammatory cells and suggest that plaque MPs promote atherosclerotic plaque progression.

So, the role of monocyte in atherosclerosis is well demonstred and since affinity of the monocyte/macrophage integrin MAC-1 $(\mathrm{CD} 11 \mathrm{~b} / \mathrm{CD} 18)$ is upregulated in inflammation, it's possible to generate a contrast agent targeting CD11b (CD11b-SPIOs) for improved macrophage detection in plaques. In a study by Von Zur Mohlen et al. [92] CD11b-SPIOs and non-targeted SPIOs (controlSPIOs) were incubated in vitro with human monocytes/macrophages. As quantified by SPIO-induced MRI signal extinction, intracellular iron-content was significantly higher in monoytes/ macrophages incubated with CD11b-SPIO than with control-SPIO in vitro $(\mathrm{p}<0.05)$, suggesting an improved uptake of CD11b-SPIOs into monocytes. Therefore, the aortic arch (AA) and vessel branches of ApoE(-/-)-knockout mice on a Western-type diet were imaged before and $48 \mathrm{~h}$ after contrast agent injection of either CD11b-SPIOs or control-SPIOs, using a $9.4 \mathrm{~T}$ animal MRI system. The SPIO-induced change in the MRI signal was quantified, as well as the macrophage-content by anti-CD68 immunhistochemistry and the iron-content by Prussian-blue staining. However, SPIO-induced signal extinction in in vivo-MRI was similar in CD11b-SPIO and control-SPIO-injected animals, with a non-significant trend towards an improved uptake of CD11b-SPIOs in the subclavian artery and subsections of the AA. These data correlated well with the results obtained by histology. Although in vitro MRI-data indicated an increased uptake of targeted CD11b-SPIOs in monocytes/macrophages, in vivo mouse data do not allow improved atherosclerotic plaque detection compared WITH non-targeted SPIOs. Therefore, CD11b-targeted MRI contrast labelling of monocytes/macrophages does not seem to be a successful strategy in stable atherosclerotic plaques such as found in the ApoE(-/-)-knockout-model. However, the impressive correlation between MRI and histology data encourages further development of inflammation- and plaque-specific contrast agents for vulnerable plaque imaging.

\section{Role of Macrophages}

Macrophages are innate immune effectors, i.e. they are activated without antigenic specificity. Macrophages are recruited and activated by many signals and have an impressive armamentarium of molecules to promote tissue damage. Macrophages play important roles in the progression of atherosclerosis by exhibiting unique characteristics under the various stimuli, evolving the plaque instability, thrombus formation and remodeling. Macrophage recruitment by abnormal endothelium over developing atherosclerotic plaques, is aided by endothelial expression of adhesion molecules (ICAM-1, VCAM, ELAM) [93]. Use of knockout mice has implicated the chemoattractant cytokine (chemokine) MCP-1 in attracting macrophage recruitment in atherosclerosis. Macrophageactivation stimuli associated with atherosclerotic risk factors include oxidised low density lipoprotein (oxLDL, "bad cholesterol"), advanced glycosylation end products (AGEs) of diabetes, angiotensin II and endothelin. Substantial work has clarified macrophage activation by OxLDL via macrophage scavenger receptors (MSRs), especially MSRA and CD36. Activated macrophages express effector molecules that kill cells and degrade extracellular matrix. These include Fas-L and nitric oxide (NO). Macrophage NO is derived from the high output inducible nitric oxide synthase (iNOS) pathway and upregulates vascular smooth muscle (VSMC) cell surface Fas, priming them for apoptosis. Activated macrophages express surface Fas-L, similar to cytotoxic T-lymphocytes and natural killer cells. Since VSMCs promote plaque stability, VSMC apoptosis may promote plaque rupture. Macrophages express multiple metalloproteinases (e.g. stromelysin) and serine proteases (e.g. urokinase) that degrade the extracellular matrix, weakening the plaque and making it rupture prone. Macrophages secrete numerous other effectors including reactive oxygen species, eicosanoids, tumour necrosis factor alpha and interleukin-1. Macrophage-derived transforming growth factor beta promotes fibrosis. Existing cardio- vascular treatments including angiotensin II receptor antagonists and angiotensin converting enzyme inhibitors, aspirin, cholesterol reduction agents especially statins may inhibit macrophages. The interaction of NO-donors with macrophages and apoptosis is complex and bifunctional [94].

A recent study [94] have shown the molecules-associated with metabolism, such as sirtuin-1 and peroxisome proliferator activated receptor gamma in macrophages, appear to be involved to modulate the atherosclerotic process.

The peroxisome-proliferator-activated receptor gamma is a member of the nuclear receptor superfamily that functions as a key transcriptional regulator of cell differentiation and lipid metabolism. Oxidized low-density lipoprotein, which plays a central role in lesion development, can activate peroxisome-proliferator-activated receptor gamma by providing the cell with oxidized fatty acid ligands of the receptor. The elucidation of a peroxisome-proliferator-activated receptor gamma signalling pathway in macrophages provides a mechanism by which oxidized lipids may directly regulate gene expression in the context of the atherosclerotic lesions. A number of potential target genes for peroxisomeproliferator-activated receptor gamma in these cells have been identified. Some, such as the type B scavenger receptor CD36 are induced by peroxisome-proliferator-activated receptor gamma ligands, whereas others, such as scavenger receptor type A, inducible nitric oxide synthetase and certain cytokines, are repressed. Given the widespread clinical use of thiazolidinediones, it is important to consider the influence of these drugs on the risk of atherosclerosis. The net effect of peroxisome-proliferator-activated receptor gamma ligands on the atherogenic process is likely to reflect a balance between local effects in the artery wall and systemic effects on lipid metabolism.

Macrophages work coordinately with other immune cells like mast cells. Macrophages are central to the initiation and progression of atherosclerosis and thus can be very appropriate targets for therapy. Cell adhesion molecules mediating monocytes recruitment to the endothelium are attractive therapy targets and their inhibitors are in clinical trials. Macrophage scavenger receptors like SR-A and CD-36 mediate foam cell formation by facilitating the uptake of modified lipids. Peroxisome proliferator-activated receptors (PPAR), liver X receptor (LXR)-mediated signaling, mitogenactivated protein kinase (MAPK) induced phosphorylation events seem to play an important role in this phenomenon. Proteins affecting macrophage cholesterol metabolism and transport, including ATP-binding cassette (ABC) A1, ABCG1, acyl-CoA: cholesterol acyltransferase (ACAT), apolipoprotein A-1 (ApoA-1), neutral cholesteryl ester hydrolase (NCEH) also regulate foam cell formation and are being developed as therapeutic targets by many pharmaceutical companies. Macrophage proliferation and apoptosis are important events controlling inflammatory response, plaque vulnerability, and destabilization [95]. Free cholesterol (FC) activates the macrophage endoplasmic reticulum (ER) stress pathway and apoptosis. Free radicals and nitric oxide also modulate macrophage foam cell formation and apoptosis. Various antioxidants like AGI-1067 and BO-653 are in clinical trials for atherosclerosis treatment. Macrophage matrix metalloproteinase's (MMP's) play a significant role in weakening and rupture of plaques. Efforts are on to develop isoform specific MMP inhibitor. CD-14, MMP-3, ABCA1, Tolllike receptor-4 (TLR-4), lectin-like oxidized low-density lipoprotein receptor-1 (LOX-1), arachidonate lipoxygenase-15 (ALOX15), and Connexin 37 polymorphisms and macrophage dysfunction signify their importance in atherosclerosis. Deciphering the role of macrophages in regulating dyslipidemia and inflammation during atherosclerosis is important for developing them as therapeutic targets.

The macrophage plays a diverse array of roles in atherogenesis and lipoprotein metabolism. The macrophage functions as a scavenger cell, an immune mediator cell, and as a source of chemotactic 
molecules and cytokines [96]. Chemokines have been implicated in promoting migration of monocytes into the arterial intima. Monocyte chemoattractant protein-1 (MCP-1) attracts monocytes bearing the chemokine receptor CCR-2. Macrophage expression of cyclooxygenase-2, a key enzyme in inflammation, promotes atherosclerotic lesion formation in low-density lipoprotein receptor (LDLR)-deficient mice. In the arterial intima, monocytes differentiate into macrophages, which accumulate cholesterol esters to form lipid-laden foam cells. Foam cell formation can be viewed as an imbalance in cholesterol homeostasis. The uptake of atherogenic lipoproteins is mediated by scavenger receptors, including SR-A and CD36. In the macrophage, ACAT-1 is responsible for esterifying free cholesterol with fatty acids to form cholesterol esters. Surprisingly, deficiency of macrophage ACAT-1 promotes atherosclerosis in LDLR-deficient mice. A number of proteins have been implicated in the process of promoting the efflux of free cholesterol from the macrophage, including apoE, ABCA1, and SRB-1. Macrophage-derived foam cells express the adipocyte fatty acidbinding protein (FABP), aP2, a cytoplasmic FABP that plays an important role in regulating systemic insulin resistance in the setting of obesity. ApoE-deficient mice null for macrophage aP2 expression develop significantly less atherosclerosis than controls wild type for macrophage aP2 expression. These results demonstrate a significant role for macrophage aP2 in the formation of atherosclerotic lesions independent of its role in systemic glucose and lipid metabolism. Furthermore, macrophages deficient in aP2 display alterations in inflammatory cytokine production. Through its distinct actions in adipocytes and macrophages, aP2 links features of the metabolic syndrome including insulin resistance, obesity, inflammation, and atherosclerosis.

Mechanisms responsible for macrophage recruitment to and retention in the vessel wall are poorly understood; however, genetic data in humans and/or mouse have implicated the macrophage chemokine receptors $\mathrm{CXCR} 2, \mathrm{CCR} 2$, and $\mathrm{CX} 3 \mathrm{CR} 1$ and their respective ligands CXCL8, CCL2, and CX3CL1, which may be induced in resident vascular cells by oxidized LDL and other factors $[97,98]$.

CX3CR1 is particularly noteworthy because both $c \times 3 \mathrm{crl}+/$ and $c \times 3 c r 1$ /_ mice have been reported to have reduced susceptibility to atherosclerosis [99-101] and because human subjects heterozygous for the $C X 3 C R 1 M 280$ allele, which encodes a defective receptor, have reduced risk of atherosclerotic cardiovascular disease [102.] CX3CR1 is an unusual chemokine receptor because, in addition to mediating leukocyte migration toward soluble CX3CL1, it is able to mediate direct adhesion of leukocytes to endothelial cells expressing a tethered form of CX3CL1 under both static and physiological flow condition.

Barlic et al. [103] showed that oxidized linoleic acid metabolites, which are components of oxidized LDL found in large amounts in atherosclerotic plaque, were able to specifically induce differentiation of human monocytes to macrophages with decreased expression of CCR2, confirming a previous report, and increased expression of CX3CR1. These macrophages acquired the ability to adhere to coronary artery smooth muscle cells. The adhesion was mediated directly and predominantly by CX3CR1.

Reciprocal effects of these lipids on CCR2 and CX3CR1 expression were mediated by the nuclear receptor peroxisome proliferator-activated receptor (PPAR) $\gamma$, and targeting the PPAR $\gamma$ gene with sRNAi dramatically reduced macrophage adhesion to coronary artery smooth muscle cells.

These data suggest that in atherogenesis oxidized lipid-driven activation of macrophage PPAR _ in the intima may result in a proadhesive chemokine receptor switch-CCR2 off, CX3CR1 oncausing cessation of CCR2-dependent migration and activation of CX3CR1-dependent retention mechanisms, which together promote macrophage accumulation in vessel wall. Our results may explain at the molecular and cell biology levels the genetic link between CX3CR1 and atherosclerosis. Moreover, they identify macrophage binding to coronary artery smooth muscle cells as the first primary cell setting in which CX3CR1 functions as the major adhesion system.

Thus, modulation of activation and function in macrophages might be a potential therapeutic target in attenuating the atherosclerosis-based cardiovascular diseases.

\section{Role of Platelets}

Beyond their role in hemostasis and thrombosis platelets are critically involved in the onset of atherosclerosis. Platelets represent an important linkage between inflammation, and atherogenesis. Platelets interact with inflammatory cells including leukocytes and endothelium. These interactions lead to leukocyte recruitment towards the vascular wall, initiating extravasation of circulating mononuclear cells and foam cell generation. Inflammatory processes within the arterial wall result in development of atherosclerotic lesions and atheroprogression. Inflammatory processes at the vascular wall result in the development of atherosclerosis. Platelet interactions with leukocytes may play a key role in the initiation of inflammation. They trigger autocrine and paracrine activation processes, leading to leukocyte recruitment (in)to the vascular wall.

The function of the endothelium is influenced by multiple factors as a consequence of cell-cell interactions. Cell-cell communication between endothelial cells with platelets has only recently begun to receive systematic study. In recent years it has been established that platelet-endothelial interactions are involved at all stages of atherosclerotic disease. From a mechanistic standpoint, platelets and endothelial cells communicate on multiple levels. Cross-talk may occur over a distance (paracrine signaling), via transient interactions (so-called give-and-go mechanism), or through receptormediated cell-cell adhesion. Platelets may release or transfer substances that influence endothelial cell function, and vice versa. Among many others, adhesion molecules, such as P-selectin (CD62P), are of special interest because of their role in modulating interactions between blood cells and the endothelium, and also because of the possible use of the soluble form as a plasma predictor of adverse cardiovascular events.

Human monocytes adhere to activated platelets, resulting in the formation of platelet-monocyte complexes (PMC). Complex formation depends on the interaction between platelet-displayed $\mathrm{P}$ selectin and the specific ligand for P-selectin on leukocytes, Pselectin glycoprotein ligand-1 (PSGL-1). We have recently shown that monocytes within PMC have increased adhesive capacity to the activated endothelium. To better understand the effect of platelet binding on the capacity of monocytes to adhere to activated endothelium, the P-selectin-PSGL-1 interaction-induced changes in integrin functionality were studied. The binding of platelets to monocytes via P-selectin-PSGL-1 interactions was shown to increase expression and activity of alpha4betal and alphaMbeta2integrin, with a concomitant decrease in L-selectin expression. Furthermore, the binding of platelets to monocytes resulted in increased monocyte adhesion to intercellular adhesion molecule-1, vascular cell adhesion molecule-1, and fibronectin. Platelet binding was also responsible for an increase in monocyte transendothelial migration. Similar effects were observed after engagement of PSGL-1 with specific antibodies or with P-selectin immunoglobulin protein. Our data suggest that platelets, by binding via $\mathrm{P}$-selectin to PSGL-1 on monocytes, induce up-regulation and activation of beta1 and beta2integrins and increased adhesion of monocytes to activated endothelium. Hence, monocytes within PMC are in a higher state of activation and may have, therefore, an increased atherogenic capacity.

The ability of platelets to activate and aggregate to form blood clots in response to endothelial injury, such as plaque rupture, is well established. These cells are therefore important contributors to 
ischaemia in atherothrombosis, and antiplatelet therapy is effective for this reason. However, growing evidence suggests that platelets are also important mediators of inflammation and play a central role in atherogenesis itself. Interactions between activated platelets, leukocytes and endothelial cells trigger autocrine and paracrine activation signals, resulting in leukocyte recruitment at and into the vascular wall. Direct physical interaction may contribute also, through platelet adhesion molecules assisting localization of monocytes to the site of atherogenesis and platelet granule release contributing to the chronic inflammatory milieu which leads to foam cell development and accelerated atherogenesis. Recent studies have shown that antiplatelet therapy in animal models of accelerated atherogenesis can lead to decreased plaque size and improve plaque stability.

\section{Interactions among Endothelial Cells, Monocytes, and T Cells}

A hallmark of atherogenesis is the upregulation of endothelial cell adhesion molecules (CAMs) and concomitant recruitment of monocytes. In atherosclerosis process molecules form on the endothelium that are responsible for the adherence, migration, and accumulation of monocytes and T cells. Such adhesion molecules, which act as receptors for glycoconjugates and integrins present on monocytes and $\mathrm{T}$ cells, include several selectins, intercellular adhesion molecules, and vascular-cell adhesion molecules. progression of atherosclerosis is currently believed to involve the interaction of monocytes with the vascular endothelium. Within the last decade, the cell-surface proteins thought to control these interactions have been investigated.

It begins with the stages of atherogenesis from the movement of the monocyte to the endothelium, followed by the migration of smooth muscle cells from the media to the intima, and subsequently to the later stages of fibrofatty plaque formation and potential complications due to thrombosis and/or plaque fissure and embolism [104]. Molecules associated with the migration of leukocytes across the endothelium, such as platelet-endothelial-cell adhesion molecules, [105] act in conjunction with chemoattractant molecules generated by the endothelium, smooth muscle, and monocytes such as monocyte chemotactic protein 1, osteopontin, [106] and modified LDL - to attract monocytes and T cells into the artery.

The recruitment of circulating monocytes occurs via a tightly regulated multi-step process mediated by a combination of cell surface adhesion molecules. Initially, activated endothelial cells at sites of incipient atherosclerosis express P-selectin, which mediates the tethering and rolling of circulating monocytes. P-selectin binds to P-selectin glycoprotein ligand-1 (PSGL-1) and other glycosylated ligands on monocytes SGL-1, the dominant ligand for all three selectins, is only functional when properly glycosylated. PSGL-1 binds P-selectin in the presence of fucosyl transferase, sialyl transferase, core 2 GlcNAc transferase and sulfatyl transferase activities [107]. All these enzymes are constitutively expressed in monocytes [108], yielding constitutively active PSGL-1. There is some evidence that E-selectin is also inducibly expressed at sites of atherosclerosis [109], and E-selectin deficiency in ApoE-null mice had a modest effect on lesion development compared to ICAM-1 and Pselectin deficiency [110]. However, functional data in relevant models that would directly support a role for this molecule are lacking.

Under normal blood flow, selectin-mediated interactions are not sufficient to arrest rolling leukocytes. It is now evident that selectins not only allow the capturing and rolling of leukocytes on the endothelium, but they also signal through PSGL-1 to activate integrins and induce monocyte activation [111]. Integrins are heterodimeric cell surface receptors and support both rolling and adhesion of leukocytes. Upon activation, integrins undergo a series of conformational changes that result in increased binding affinity for their respective ligands [112].
Atherosclerotic lesions are thought to start by subendothelial low-density lipoprotein (LDL) accumulation, which leads to endothelial cell (EC) activation and chronic inflammation. The endothelium is the primary barrier between blood and tissues. However, ECs are susceptible and sensitive to the shear stresses provided by blood flow, which can change their morphology and trigger many signaling cascades [113]. LDL accumulation preferentially occurs at sites of arterial branching or curvature, where flow is disturbed, in contrast to areas of continuous laminar flow, which are not or less affected. There is a positive correlation between areas of low shear stress and sites of LDL accumulation and lesion initiation [114]. Hyperlipidemia, due to both genetic and environmental factors increases the risk of atherosclerosis, as greater circulating LDL levels lead to increased accumulation. platelet activation promotes the adhesive interaction between monocytes and endothelial cells during atherosclerosis. It is believed that aggregation of activated platelets with circulating monocytes promotes monocyte-endothelial interactions by deposition of proinflammatory chemokines and P-selectin expression [115] Indeed, CCL5 deposition by platelets on activated endothelium induces arrest of rolling monocytes [116,119]. In addition, the combination of platelet-derived platelet factor 4 (PF4/CXCL4) with CCL5 results in an effect greater than CCL5 alone. Furthermore, P-selectin-mediated rolling of activated platelets on inflamed endothelium is important for the progression of atherosclerotic lesions. Although some ECs express functional PSGL-1 [117], the endothelial ligand for platelet P-selectin in atherosclerotic lesions is unknown. P-selectin-expressing platelets injected into Apoe-/- mice accelerated the formation of atherosclerotic lesions [118], whereas injection of P-selectin-deficient platelets resulted in smaller lesions. This finding is supported by bone marrow transplantation experiments suggesting that platelet and not endothelial P-selectin drives atherosclerosis. Recently, Tsou et al. [120] aimed to understand how endothelial cells sense a gradient of fluid shear stress and transduce signals that regulate membrane expression of cell adhesion molecules and monocyte recruitment. In this study human aortic endothelial cells were stimulated with TNFalpha and simultaneously exposed to a linear gradient of shear stress that increased from 0 to $16 \mathrm{dyne} / \mathrm{cm} 2$. Cell adhesion molecule expression and activation of NFkappa B were quantified by immunofluorescence microscopy with resolution at the level of a single endothelial cell. Monocyte recruitment was imaged using custom microfluidic flow chambre. VCAM-1 and E-selectin upregulation was greatest between 2-4 dyne/cm2 (6 and 4-fold, respectively) and above 8 dyne/cm 2 expression was suppressed below that of untreated endothelial cells. In contrast, ICAM-1 expression and NFkappa B nuclear translocation increased with shear stress up to a maximum at 9 dyne/cm2. Monocyte recruitment was most efficient in regions where E-selectin and VCAM-1 expression was greatest. On this basis authors found that the endothelium can sense a change in shear stress on the order of 0.25 dyne/cm 2 over a length of approximately 10 cells, regulating the level of protein transcription, cellular adhesion molecule expression, and leukocyte recruitment during inflammation.

In certain pathological conditions, such as atherosclerosis, endothelial function is chronically disturbed, and this alteration is a critical step in the progression of the disease. In recent years, advances in knowledge have improved our understanding of the physiopathology of atherosclerosis, which is now known to be a dynamic and progressive process proceeding from endothelial dysfunction and inflammation of the vascular wall. The evolution and prognosis of atherosclerosis, along with the efficacy of therapeutic modalities, can be assessed by measuring the circulating levels of various biomarkers expressed or released by the endothelium.

Platelets represent an important linkage between inflammation, thrombosis, and atherogenesis. Inflammation is characterized by interactions among platelets, leukocytes, and ECs. These interactions trigger autocrine and paracrine activation processes that lead 
to leukocyte recruitment into the vascular wall. Platelet-induced chronic inflammatory processes at the vascular wall result in development of atherosclerotic lesions and atherothrombosis.

During the adhesion process, platelets become activated and release an arsenal of potent inflammatory and mitogenic substances into the local microenvironment, thereby altering chemotactic, adhesive, and proteolytic properties of ECs [121].

These platelet-induced alterations of the endothelial phenotype support chemotaxis, adhesion, and transmigration of monocytes to the site of inflammation. Released from dense granules, 〈-granules, lysosomes, the canalicular system, or the cytosol, platelets secrete or expose adhesion proteins (e.g, fibrinogen, fibronectin, vWF, thrombospondin, vitronectin, P-selectin, GPIIb/IIIa), growth factors (e.g, PDGF, TGF- ${ }^{\circledR}$, EGF, bFGF), chemokines (e.g, RANTES, platelet factor 4 [CXC chemokine ligand 4], epithelial neutrophilactivating protein 78 [CXC chemokine ligand 5]), cytokine-like factors (e.g, IL-1, CD40 ligand, thromboglobulin), and coagulation factors (e.g, factor V, factor XI, PAI-1, plasminogen, protein S). These proteins act in a concerted and finely regulated manner to influence widely differing biological functions such as cell adhesion, cell aggregation, chemotaxis, cell survival and proliferation, coagulation, and proteolysis, all of which accelerate inflammatory processes and cell recruitment. For example, IL-1 $\beta$ has been identified as a major mediator of platelet-induced activation of ECs [122.]. The IL-1 $\beta$ activity expressed by platelets appears to be associated with the platelet surface, and coincubation of ECs with thrombin-activated platelets induces IL-1 $\beta$-dependent secretion of IL-6 and IL-8 from ECs [123]. Furthermore, incubation of cultured ECs with thrombin-stimulated platelets significantly enhances the secretion of endothelial monocyte chemoattractant protein-1 (MCP1 ) in an IL-1 $\beta$-dependent manner. MCP-1 belongs to the CC family of chemokines and is thought to play a key role in the regulation of monocyte recruitment to inflamed tissue and in atherosclerosis $[124,125]$.

Moreover, A finely regulated functional interaction of platelets with chemokines has also been implicated in atherogenesis [126]. Activated platelets can release chemokines and can induce the secretion of chemokines in various cells of the vascular wall; in turn, certain chemokines can enhance platelet aggregation and adhesion in combination with primary agonists and can trigger monocyte recruitment. One such candidate for monocyte recruitment is RANTES, which has been shown to trigger monocyte arrest on inflamed and atherosclerotic endothelium [127]. Deposition of plateletderived RANTES induces monocyte recruitment mediated by Pselectin [128]. Another platelet-derived chemokine is platelet factor 4 (PF4), the most abundant protein secreted by activated platelets. First, PF4 acts as a chemoattractant for monocytes promoting their differentiate on into macrophages [129]. Second, PF4 may directly aggravate the atherogenic actions of hypercholesterolemia by promoting the retention of lipoproteins.

Sachais and colleagues have recently shown that PF4 can facilitate the retention of LDL on cell surfaces by inhibition of its degradation by the LDL receptor [130]. In addition, PF4 markedly enhances the esterification and uptake of oxidized LDL by macrophages [131]

With the help of intravital microscopy and the availability of appropriate atherosclerotic animal models, it has become evident that platelets adhere to the arterial wall in vivo even in the absence of EC denudation [132]. Theilmeier and coworkers found in hypercholesteremic rabbits that platelets adhere to predilection sites of atherosclerosis before lesions are detectable [133].

Substantial platelet adhesion to the carotid artery early in atherogenesis involved both platelet $\mathrm{GPIb}\langle$ and $\langle\operatorname{IIb} \beta)$. Platelet adhesion to the carotid wall coincided with inflammatory gene expression and preceded the invasion of leukocytes [134]. Prolonged antibody blockade of platelet GPIb<profoundly reduced leukocyte accumulation in the arterial intima and attenuated atherosclerotic lesion formation. Moreover, apoEdeficient mice lacking GPIIb exhibit substantially reduced formation of atherosclerotic lesions [135]. Further, circulating activated platelets and plateletleukocyte/monocyte aggregates promote formation of atherosclerotic lesions [136]. The importance of $\mathrm{P}$-selectin for atherosclerotic lesion development has also been described [137-139]. The importance of platelets in development of atherosclerosis is also documented by Belton et al, who showed that inhibition of COX-1, an enzyme that is exclusively present in platelets, prevented gross lesion formation in apoE-/- mice [140]. Interestingly, effective inhibition of downstream activation cascades can also effectively inhibit atherosclerosis in various models. The body of evidence implicating the CD40-CD40L system in atherogenesis is compelling:

Disruption of CD40-CD40L in mouse models of atherosclerosis both downregulated early disease events such as initial plaque formation [141,142] and could halt the progression of established lesions to more advanced unstable lesions [143].

In humans an increase in systemic platelet activation has been described for a variety of atherosclerotic diseases, including coronary artery disease [144], transplant vasculopathy [145], and carotid artery disease [146]. Recently, it was found that activation of circulating platelets is associated with enhanced wall thickness of the carotid artery in humans [147].

On this basis several lines of evidence indicate that platelets are potent inflammatory cells that induce inflammatory responses in adjacent cells such as leukocytes and endothelial cells. Platelets may also themselves respond to inflammatory mediators produced by these neighboring cells. These platelet-mediated inflammatory pathways contribute to atherogenesis in both the early and late stage of the process.

Platelets not only play a role in the late complications of atherosclerosis, but are also essential in its initiation, interacting with endothelial cells and leukocytes. Platelet adhesion to injured or atherosclerotic vessels is critical for the initiation of atherosclerotic lesion formation in vivo. Increasing evidence has recently highlighted the role of progenitor cells in inflammation, atherogenesis, and atheroprogression. Recruitment of progenitor and dendritic cells to sites of vascular injury is poorly understood so far. Both human progenitor and dendritic cells [148] significantly adhere to platelets, indicating that platelets adherent to collagen or to endothelial cells can serve as a bridging mechanism directing circulating progenitor and dendritic cells to sites of impaired vasculature. Moreover, platelets regulate differentiation of progenitor cells to endothelial cells or macrophages and foam cells and modulate essential functions of dendritic cells, including their activation, differentiation and apoptosis in vitro.

Recruitment of human CD34+ progenitor cells toward vascular lesions and differentiation into vascular cells has been regarded as a critical initial step in atherosclerosis. To investigate whether platelets are involved in progenitor cell recruitment and differentiation into endothelial cells and foam cells, Daub et al. [149] examined the interactions of platelets and CD34+ progenitor cells. Cocultivation experiments showed that human platelets recruit CD34+ progenitor cells via the specific adhesion receptors P-selectin/PSGL-1 and beta1- and beta2-integrins. Furthermore, platelets were found to induce differentiation of CD34+ progenitor cells into mature foam cells and endothelial cells. Platelet-induced foam cell generation could be prevented partially by HMG coenzyme A reductase inhibitors via reduction of matrix metalloproteinase-9 (MMP-9) secretion. Finally, agonists of peroxisome proliferator-activated receptoralpha and -gamma attenuated platelet-induced foam cell generation and production of MMP-9. This study describes a potentially important mechanism of platelet-induced foam cell formation and generation of endothelium in atherogenesis and atheroprogression. 
The understanding and modulation of these mechanisms may offer new treatment strategies for patients at high risk for atherosclerotic diseases

The bidirectional interaction between platelets and other cells may also be involved in the nonresolving inflammation characterizing atherosclerosis. In patients with atherosclerotic disorders, platelet-mediated inflammation appears to be operating in spite of the wide use of platelet-inhibiting drugs.

On this basis nevertheless, platelets are generally not believed to be involved in the initiation of atherosclerosis. more recently The involvement of platelets in the initiation of atherosclerotic lesion formation had become critical in directing the atherosclerotic process into regeneration or ongoing vascular injury.

Platelets internalize oxidized phospholipids and promote foam cell formation. Platelets also recruit circulating blood cells including progenitor cells to the vessel, that are able to differentiate into foam cells or endothelial cells depending on conditions. Platelets express various scavenger receptors that are able to regulate LDLuptake. LDL-laden platelets are internalized by adherent progenitor cells that in turn differentiate into macrophages and foam cells.

An expanding body of evidence continues to build on the role of platelets as initial actors in the development of atherosclerotic lesions. Platelets bind to leukocytes, endothelial cells, and circulating progenitor cells and initiate monocyte transformation into macrophages. Therefore platelets regulate the initiation, development and total extent of atherosclerotic lesions.

\section{MICROBES, INFLAMMATION AND ATHEROSCLEROSIS}

Among the multiple factors involved in the pathophysiology of heart disease, infections have been proposed to play a role in atherosclerosis with most of the available evidence implicating Chlamydia pneumonia, influenza virus and Mycoplasma pneumoniae. Based on a model case presentation, we speculate that in the absence of traditional risk factors and in the context of an ongoing respiratory infection caused by a pro-inflammatory pathogen (M. pneumoniae) along with a past positive serologic history for potentially proven atherogenic microorganism (C. pneumoniae) and infection may elicit potentially pathogenic events on vascular wall cells and leukocytes of atheromatous lesions, supporting the hypothesis that such infections may potentiate atherosclerotic cardiovascular disease (CVD)

The recognition of atherosclerosis as an inflammatory disease in its genesis, progression and ultimate clinical manifestations has created an interesting area of vascular research. Apart from those well-known traditional risk factors for atherosclerosis, novel and potentially treatable atherosclerotic risk factors such as homocysteine (an amino acid derived from the metabolism of dietary methionine that induces vascular endothelial dysfunction) and infections have emerged. In fact, the century-old 'infectious' hypothesis of atherosclerosis has implicated a number of micro-organisms that may act as contributing inflammatory stimuli. Although cytomegalovirus, Helicobacter pylori and Chlamydia pneumoniae are the three micro-organisms most extensively studied, this review will focus on C. pneumoniae. Collaborative efforts from many disciplines have resulted in the accumulation of evidence from seroepidemiological, pathological, animal model, immunological and antibiotic intervention studies, linking $\mathrm{C}$. pneumoniae with atherosclerosis. Seroepidemiological observations provide circumstantial evidence, which is weak in most prospective studies. Pathological studies have demonstrated the preferential existence of C. pneumoniae in atherosclerotic plaque tissues, while animal model experiments have shown the induction of atherosclerosis by C. pneumoniae. Finally, immunological processes whereby C. pneumoniae could participate in key atherogenic and atherothrombotic events have also been identified. Although benefits of the secondary prevention of atherosclerosis have been demonstrated in some antibi- otic intervention studies, a number of negative studies have also emerged.

Atherosclerosis can be apparently the result of ultrachronic persistent infection by Chlamydia pneumoniae and not the result of different risk factors. The main arguments for the chlamydial genesis are: 1) Correlation of coronary heart disease and other atherosclerotic disease with antibodies against C. pneumoniae; 2) C. pneumoniae could be detected with different techniques (PCR, immunohistology, electromicroscopy, culture) in a high percentage in atheromas from different sites; 3) Three international studies with macrolides in coronary heart disease were successful; 4) The target cells of atherosclerosis (endothelia, macrophages, muscle cells) can be infected by $\mathrm{C}$. pneumoniae in vitro; 5 . Positive animal experiments.

The Koch-Henle criteria for the proof of the etiology are largely fulfilled--even if there are doubts about the validity of these criteria in chronic local infections. A number of unexplainable aspect of atherosclerosis can be seen in a new light. The higher incidence of coronary heart disease in young males has a parallel in the remarkable androtropism of many bacterial diseases (pneumococcal pneumonia, tuberculosis). The reduction of incidence of atherosclerotic diseases since 1965 can be explained by the much higher intake of doxycyclin and macrolides. The low incidence of coronary heart disease in France--sometimes regarded as an effect of red wine--can be explained as a result of a much higher use of antichlamydial antibiotics. The increase of inflammatory parameters $(\mathrm{C}$ reactive protein, fibrinogen, leucocytes) before acute coronary infarction are not risk factors but signs of an active chronic infection. The interpretation is possible, that atherogenic changes in lipids like increase of LDL and decrease of HDL are not risk factors but consequence of chronic arterial infection by chlamydia. The low incidence of atherosclerosis in the tropics--despite high frequency of chlamydial infection--is difficult to explain. Vascular infection can be related with the age of the patient at the primary infection. With low hygiene, intestinal primary infections in early childhood can be possible. Arterial infection would be thus a result of a primary infection in adolescence ("yet another poliomyelitis story"). There are good arguments for the thesis that $\mathrm{C}$. pneumoniae is the primary cause of atherosclerosis and not a secondary invader. The consequence, nevertheless, is similar: Antibiotics get a key role. The macrolides roxithromycin, azithromycin, clarithromycin and the tetracyclin doxycyclin fulfill the criteria as potential antichlamydial agents. In general a longer treatment ( 6 to 8 to 12 weeks) seems advisable. It is necessary to start international studies with antibiotics in coronary infarction and other clinical manifestations of atherosclerosis. The relevant antibiotics licensed for chlamydial infections are cheap and safe.

Song et al. [150] hypothesized that a vascular infection with C. pneumoniae may induce a chronic inflammatory reaction in the host vascular tissue and activated inflammatory cells may express inflammatory mediators such as cyclooxygenase-2 (COX-2) and matrix metalloproteinases (MMPs). At first, we evaluated the relationship between C. pneumoniae infection and atherosclerosis indirectly by serologic study, and then, to confirm our hypothesis, we performed an immunohistochemical study of atherosclerotic plaques. The seropositive rate of anti-Chlamydia pneumoniae IgG was higher in the disease group (Group I, 59.8\%, $\mathrm{n}=254$ ) than in the negative control group (Group III, $47.4 \%, n=97)(p=0.041)$, but the anti-Chlamydia pneumoniae IgA was not different in seropositivity between the two groups (Group I, 64.6\%; Group III, $57.7 \%$ ). The simultaneous seropositive rates of both $\operatorname{IgG}$ and $\operatorname{IgA}$ were $56.7 \%$ in Group I and $43.3 \%$ in Group III ( $p=0.033)$. In subgroups without the conventional risk factors of atherosclerosis, these findings were more prominent. Furthermore, we performed immunohistochemical staining on the atherosclerotic aortic tissues obtained from patients that were seropositive to C. pneumoniae ( $\mathrm{n}=$ 5), by using antibodies to C. pneumoniae, COX-2, and MMP-9. The 
immunoreactivity for COX-2 and MMP-9 increased in the atherosclerotic plaques itself, predominantly in the surrounding area of immunoreactive C. pneumoniae. These findings support our hypothesis and C. pneumoniae may participate in a pathogenetic mechanism for atherogenesis or progression of atherosclerosis.

Furthermore, Blasi et al. [151] studied 51 patients (mean age, 68.3 years) who underwent abdominal aortic aneurysm surgery. For each patient authors performed a microimmunofluorescence test for immunoglobulin G (IgG), IgA, and IgM antibodies to C. pneumoniae specific antigen (TW-183). Anti-H. pylori antibodies were determined by means of an EIA-G test. Each aortic aneurysm surgical specimen was sampled into multiple sections of $0.3 \mathrm{~cm} 2$ each and frozen at -20 degrees $\mathrm{C}$. Two samples of each aneurysm were used for a nested PCR with two sets of C. pneumoniae and two sets of H. pylori specific primers. Specimens were treated with a solution containing $20 \mathrm{mM}$ Tris-HCl, Tween 20 -Nonidet P-40 $(0.5 \%$ [vol/vol] each), and 100 micrograms of proteinase $\mathrm{K}$ per $\mathrm{ml}$ and incubated at 60 degrees $\mathrm{C}$ for $1 \mathrm{~h}$ and at 98 degrees $\mathrm{C}$ for $10 \mathrm{~min}$. DNA was extracted twice with phenol-chloroform-isoamylic alcohol and precipitated with sodium acetate-ethanol by standard methods. Forty-one patients were seropositive for C. pneumoniae with past-infection patterns in 32 patients $(16<$ or $=\operatorname{IgG}<512 ; 32<$ or $=\operatorname{IgA}<256)$ and high antibody titers in 9 patients $(\operatorname{IgG}>$ or $=$ 512). In 26 of 51 patients, C. pneumoniae DNA was detected in aortic aneurysm plaque specimens. Of these patients, 23 had a serologic past-infection pattern, 2 had an acute reinfection pattern, and 1 was seronegative. Forty-seven of 51 patients were seropositive for H. pylori. In all cases PCR showed no evidence of H. pylori presence in plaque specimens. This study provides data on a possible $\mathrm{C}$. pneumoniae involvement in the pathogenesis of aortic aneurysm and additional evidence for an association between this agent and atherosclerosis.

Mayr M et al. [152] evaluated cardiovascular risk factors as well as seropositivity to Chlamydia pneumoniae, Helicobacter pylori, and cytomegalovirus in a population-based study. A significant association between prevalence and severity of atherosclerosis in carotid and femoral arteries and $\operatorname{IgA}$ antibodies to $\mathrm{C}$ pneumoniae was demonstrated that was not substantially altered after adjustment for established risk factors. For anti-H pylori IgG antibodies, significant correlations to vascular disease were restricted to low social status and lesions in carotid arteries. In addition, the study design allowed us to monitor lesion progression over time. In this prospective analysis, $\mathrm{C}$ pneumoniae seropositivity emerged as a significant risk predictor. Antibody titers against cytomegalovirus were not a marker for prevalence or incidence of atherosclerosis in this population. Further infection parameters added to the predictive value of chlamydial serology in risk assessment. Mean odds ratios for the prevalence of carotid atherosclerosis were 4.2 and 6.3 for seropositive subjects with elevated C-reactive protein levels and clinical evidence for chronic respiratory infection, respectively. For subjects with all 3 infection parameters, the odds ratio of carotid atherosclerosis reached $10.3(\mathrm{P}<0.0001)$. Concomitantly, serum antibodies to mycobacterial heat-shock protein 65 (mHSP65) correlated with seropositivity to $\mathrm{C}$ pneumoniae and $\mathrm{H}$ pylori but not to cytomegalovirus. This prospective population-based study provides strong evidence for a potential atherogenic role of persistent bacterial infection, especially $\mathrm{C}$ pneumoniae, as indicated by serological and clinical data and demonstrates a correlation between immune reactions to mHSP65 and bacterial infections in atherogenesis.

\section{Genetic Susceptibility and Inflammatory Gene Polymorphisms in Atherogenesis}

Development of atherosclerotic plaques represents a complex interplay of environmental risk factor exposure and a multigenic profile with intermediate phenotypes. It is becoming more widely accepted that individual patient phenotypic variants in plaque instability is unexplained solely by risk factor exposure and that differences in distribution of polymorphisms in genes coding for inflam- matory factors may account for the patterns of behavior in carotid atherosclerotic.

Several studies showed a profile of genetic markers and single nucleotide polymorphisms that define with greater specificity the susceptibility of an individual for atherosclerosis development based on gene presence as well as gene- gene interaction. Many of the genes that regulate inflammatory cytokine and adhesion molecules are polymorphic in nature.

Plaque. Although large epidemiological studies confirm the hereditary contribution to cerebrovascular risk [153] the quantification of genetic factors for large-vessel disease remains to be defined. frequency of specific alleles for cytokines such as TNF- $\alpha$ and IL-1 $\beta$ have been associated with other inflammatory diseases $[154$, $155,158]$.

To explain the presence of these seemingly injurious proinflammatory gene polymorphisms, genes that increase proinflammatory expression from an evolutionary prospective may have provided an advantage to our ancestors, including allowance for wound healing and eradication of infection during periods of nutritional deprivation. These same genes may now confer selective disadvantages in modern times, particularly given the average life span increases, environmental stresses, and western diet/lifestyle that could lead to insulin resistance and atherosclerosis [156-158].

Numerous gene polymorphisms associated with the development of coronary and carotid atherosclerotic disease have now been identified. For example, a large population-based study revealed a strong association in the gene encoding phosphodiesterase 4D (PDE4D) for carotid and cardiogenic stroke. Haplotype identification was essential for determining phenotypic expression. This gene revealed 3 distinct groups characterized by wild-type, at-risk, and protective haplotype classification [159]. Other genes showing significant association with the development of atherosclerotic disease include IL-1 receptor antagonist, in which the homozygous carrier state for allele 2 imparts an adjusted odds ratio (OR) of 13.78 for a greater likelihood of atherosclerosis [160] Also, Tolllike receptor-4 polymorphism Asp299Gly is associated with an alteration in inflammatory expression and acute coronary events [161].

Moreover, current evidence favours an interaction of multiple environmental and genetic factors in the initiation and progression of AAA. Epigenetics is the term used to define the properties of the genome that are not explained by the primary sequence, but are due to the modifications of DNA and/or associated proteins. Previous research indicates the association of gene specific promoter DNA hyper-methylation and global DNA hypo-methylation with atherosclerosis. Evidence also suggests an important role for epigenetic processes such as histone acetylation in cardiovascular diseases including atherosclerosis and restenosis. Altered DNA methylation or histone acetylation occur in inflammation, cellular proliferation and remodelling processes and therefore maybe relevant to the pathology of AAA. Important risk factors for AAA, including cigarette smoking, older age, male gender and hypertension, have been linked with epigenetic effects and thus could act in this way to promote AAA. In this review, we discuss the potential role of epigenetic mechanisms in AAA. Since epigenetic alterations are to some extent reversible, further study of this area may identify new treatment targets for AAA.

Jerrard-Dunne $P$ et al. [162] examined the impact of inflammatory gene polymorphisms and gene-smoking interactions on common carotid artery intima-media thickness (IMT), a measure of early atherosclerosis. In a community population $(n=1000)$, mean IMT was determined using ultrasound. This population was genotyped for 6 polymorphisms in 4 inflammatory genes: IL-6-174, IL6-572, and IL-6-597; IL-1-beta-31; IL-1 receptor antagonist VNTR and CD14-159. Serum IL-6 levels were measured in the first 500 subjects. Genotypes/haplotypes associated with higher IL-6 levels 
were designated "inflammatory haplotypes. A gene load score was calculated, in which 2 represented individuals homozygous for $>$ or $=2$ inflammatory genotypes/haplotypes and 0 was homozygous for none. Increasing gene load of inflammatory genotypes was associated with a linear increase in serum IL-6 levels $(\mathrm{P}=0.018)$ and increased carotid artery IMT $(\mathrm{P}=0.003)$. There was a significant interaction between gene load and smoking status on carotid IMT (P for interaction=0.002). Specifically, in smokers, carriers of inflammatory haplotypes had significantly increased age- and sex-adjusted IMT (IL-6-174C/IL-6-572G/IL-6-597A, $\mathrm{P}=0.005$; IL-1-beta$31 \mathrm{~T} / \mathrm{IL}-1 \mathrm{RN} * 2, \mathrm{P}=0.04 ; \mathrm{CD} 14-159 \mathrm{CC}, \mathrm{P}=0.028$ ). These findings support the hypothesis that inflammation and cytokine responses provide a key mechanism by which smoking causes atherogenesis. Secondly, they highlight the importance of gene-environment, and gene-gene-environment interactions in the pathogenesis of atherosclerosis.

Another study extended [163] the analysis by inclusion of other inflammatory conditions (chronic infection and obesity/abnormal glucose tolerance). In this study common carotid and femoral artery IMT was determined in the Bruneck Study population $(n=810)$. Proinflammatory variants were determined in 3 genes (IL-6 [-174C, $-572 \mathrm{G},-597 \mathrm{~A}$ haplotype], IL-1-receptor antagonist [VNTR *2], and endotoxin receptor CD-14 [-159C]). There was a significant relationship between gene-variant score and carotid IMT: age- and sexadjusted mean IMT in subjects with 0,1 , and $>$ or $=2$ gene variants was 936, 987 and 1047 microm, respectively $(\mathrm{P}=0.001)$, and synergistic effects of gene-variant score and smoking on IMT measurements $(\mathrm{P}=0.040)$. Analogous findings were obtained for obesity/abnormal glucose tolerance and chronic infection. Interactive effects of gene-variant score and a risk factor score composed of the acquired inflammatory conditions were highly significant $(\mathrm{P}<0.001$ each). Results were similar for femoral artery IMT.

These results provide support for a causal role of inflammation in carotid atherosclerosis, and emphasize the importance of genegene and gene-environment interactions in this pathogenic pathway. This may help to explain the substantial variability of disease expression in subjects with proinflammatory risk factors such as smoking, diabetes and chronic infection.

Given the important role of Ang II/Ang 1-7 in atherogenesis, Thomas et al. [164] investigated the impact of ACE2 deficiency on the development of atherosclerosis. C57B16, Ace2 knockout (KO), apolipoprotein E (ApoE) $\mathrm{KO}$ and ApoE/Ace2 double $\mathrm{KO}$ mice were followed until 30 weeks of age. Plaque accumulation was increased in ApoE/Ace2 double KO mice when compared to ApoE $\mathrm{KO}$ mice. This was associated with increased expression of adhesion molecules and inflammatory cytokines, including interleukin6 , monocyte chemoattractant protein-1, and vascular cell adhesion molecule-1, and an early increase in white cell adhesion across the whole aortae on dynamic flow assay. In the absence of a proatherosclerotic (ApoE KO) genotype, ACE2 deficiency was also associated with increased expression of these markers, suggesting that these differences were not an epiphenomenon. ACE inhibition prevented increases of these markers and atherogenesis in ApoE/ACE2 double $\mathrm{KO}$ mice. Bone marrow macrophages isolated from Ace2 KO mice showed increased proinflammatory responsiveness to lipopolysaccharide and Ang II when compared to macrophages isolated from C57B16 mice. Endothelial cells isolated from Ace2 $\mathrm{KO}$ mice also showed increased basal activation and elevated inflammatory responsiveness to TNF- $\alpha$. Similarly, selective inhibition of ACE2 with MLN-4760 also resulted in a proinflammatory phenotype with a physiological response similar to that observed with exogenous Ang II (10(-7) mol/L).

Genetic Ace2 deficiency is associated with upregulation of putative mediators of atherogenesis and enhances responsiveness to proinflammatory stimuli. In atherosclerosis-prone ApoE KO mice, these changes potentially contribute to increased plaque accumula- tion. These findings emphasize the potential utility of ACE2 repletion as a strategy to reduce atherosclerosis.

Tenascin-C (TNC) is an extracellular matrix protein implicated in biological processes important for atherosclerotic plaque development and progression, including smooth muscle cell migration, proliferation and inflammation. Very recently Minear et al. [165] investigated whether common genetic variation within TNC is associated with risk of atherosclerosis and coronary artery disease (CAD) in three independent datasets. Authors genotyped 35 single nucleotide polymorphisms (SNPs), including 21 haplotype tagging SNPs, in two of these datasets: human aorta tissue samples $(n=205)$ and the CATHGEN cardiovascular study $(n=1,325)$. Eleven of these 35 SNPs were then genotyped in a third dataset, the GENECARD family study of early-onset CAD ( $\mathrm{n}=879$ families). Three SNPs representing a block of linkage disequilibrium, rs3789875, rs12347433, and rs4552883, were significantly associated with atherosclerosis in multiple datasets and demonstrated consistent, but suggestive, genetic effects in all analyses. In combined analysis rs3789875 and rs12347433 were statistically significant after Bonferroni correction for 35 comparisons, $\mathrm{p}=2 \times 10(-6)$ and $5 \times 10(-6)$, respectively. The SNP rs12347433 is a synonymous coding SNP and may be biologically relevant to the mechanism by which tenascin-C influences the pathophysiology of CAD and atherosclerosis. This is the first report of genetic association between polymorphisms in TNC and atherosclerosis or CAD.

$\mathrm{F} 11 \mathrm{R}$ is the gene name for an adhesion protein, called the F11receptor, aka JAM-A, which under normal physiological conditions is expressed constitutively on the surface of platelets and localized within tight junctions of endothelial cells (EC). Previous studies of the interactions between human platelets and EC suggested that F11R/JAM-A plays a crucial role in inflammatory thrombosis and atherosclerosis. A study by Babinska et al. [166] reported a obtained in-vivo confirmation o by investigating F11R/JAM-A protein and mRNA in patients with aortic and peripheral vascular disease and in an animal model of atherosclerosis. Molecular and immunofluorescence determinations revealed very high levels of F11R/JAM-A mRNA and F11R/JAM-A protein in atherosclerotic plaques of cardiovascular patients. Similar results were obtained with 12-week-old atherosclerosis-prone apoE-/- mice, an age in which atherosclerotic plaques are well established. Enhanced expression of the F11R/JAM-A message in cultured EC from human aortic and venous vessels was observed following exposure of the cells to cytokines. Determinations of platelet adhesion to cultured EC inflamed by combined cytokine treatment in the presence of F11R/JAM-A - antagonists provided data indicating that de novo expression of F11R/JAM-A on the luminal surface of inflamed EC has an important role in the conversion of EC to a thrombogenic surface. Further studies of these interactions under flow conditions and under in-vivo settings could provide a final proof of a causal role for F11R/JAM-A in the initiation of thrombosis

On the basis of this study that have determined that the F11 receptor (F11R; aka JAM-A) exerts a critical force in the adhesion of human platelets to inflamed endothelial cells (ECs), and thus can play a significant role in the initiation of atherosclerotic plaque formation, the same group of researchers focused on a subsequent event in plaque development--the migration of smooth muscle cells (SMCs) from the media to the intima of inflamed vessels. Authors investigated [167] of the expression of F11R in atherosclerotic arteries of coronary artery disease (CAD) patients, and of the role of F11R in the migration of SMCs involved in atherogenesis. Histological staining and specific-antibody immunofluorescence of excised, human atherosclerotic coronary arteries revealed the expression of F11R in the SMCs of the intima. RT-PCR and SDSPAGE followed by immunoblotting procedures demonstrated that F11R mRNA and the F11R protein levels were enhanced by the stimulation of cultured human aortic SMCs with a combined treatment of proinflammatory cytokines (TNFalpha+INFgamma+IL- 
beta1). Neither the F11R message nor protein was expressed in non-stimulated SMCs. The functional role of F11R in SMCs' migration was studied in cytokine-stimulated SMCs by interference of F11R expression with siRNA. Silencing of the F11R gene of cytokines-treated SMCs inhibited the expression of both F11R mRNA and F11R protein. Functionally, silencing of the F11R gene blocked the proliferation and migration of these inflamed SMCs, both critical events in atherogenesis.

The new findings of this study are that F11R mRNA and F11R protein are expressed in SMCs of the intima (but not in the media) of atherosclerotic arteries of CAD patients, and that F11R is required for the proliferation and migration of inflamed SMCs. Based on these findings, we conclude that in addition to the previously reported role of $F 11 R$ in the initiation of plaque formation, F11R plays also an important role in the subsequent growth of atherosclerotic plaques. Identification of drugs that interfere with these pathophysiologic actions of F11R thus represents an effective new approach for the prevention and treatment of atherosclerosis, heart attacks and stroke.

Serum chemokine CXC Ligand 16 (CXCL16) concentration is associated with atherosclerosis and CXCL16 expression may be influenced by the polymorphismA181V, Wang et al. [168] established whether serum CXCL16 concentration or the A181V genotype is more strongly associated with atherosclerotic stroke and its associated risk factor, carotid atherosclerosis. Authors used PCRRFLP to genotype 244 atherosclerotic stroke patients (AS group), 153 stroke-free controls (patient controls) and 167 healthy controls. Serum CXCL16 concentration was determined for a subset of patients $(n=135)$ and all controls. The same subset of patients was then examined using ultrasound to evaluate their carotid atherosclerotic lesions, including intima-media thickness (IMT), plaque stability and carotid plaque area (CPA). Compared with the patient controls and healthy controls, serum CXCL16 concentration was significantly increased in the AS group $(P<0.05$, and 0.01$)$. It was also strongly associated with increased IMT, vulnerable plaque and increased CPA $(P<0.05,<0.001$, and $<0.01)$. However, the CXCL16 A181V genotype distribution and allele frequencies showed no differences between AS and control groups, nor did it influence serum CXCL16 concentration. Authors concluded that serum CXCL16 concentration is significantly associated with atherosclerotic stroke and carotid atherosclerosis, suggesting that this biochemical test may be useful to identify patients at increased risk of atherosclerosis.

\section{CELL TRAFFICKING IN ATHEROSCLEROTIC LESIONS}

The accumulation of smooth muscle cells (SMCs) plays a principal role in atherogenesis, post-angioplasty restenosis and transplantation-associated vasculopathy. Therefore, much effort has been expended in targeting the migration and proliferation of medial smooth muscle cells to prevent occlusive vascular remodeling. Recent evidence suggests that bone marrow-derived circulating precursors can also give rise to endothelial cells and smooth muscle cells that contribute to vascular repair, remodeling, and lesion formation under physiological and pathological conditions.

It has been assumed that smooth muscle cells derived from the adjacent medial layer migrate, proliferate and synthesize extracellular matrix. Although much effort has been devoted, targeting migration and proliferation of medial smooth muscle cells, no effective therapy to prevent occlusive vascular remodeling has been established. It was suggested that bone marrow cells may have the potential to give rise to vascular progenitor cells that home in the damaged vessels and differentiate into smooth muscle cells or endothelial cells, thereby contributing to vascular repair, remodeling, and lesion formation.

Fischietti et al. [169] evaluated in 2 groups of diabetic or nondiabetic Wistar rats the occurrence of basal or stimulated stable adherence to the endothelial layer and extravasation of circulating fluorescently-labelled leukocytes was assessed by using an in vivo videomicroscopy technique. In a second part of the study, the development of vascular damage in short term diabetes was studied in the genetically $\mathrm{C} 6$ deficient rats of the PVG strain, and compared with those observed in the wild-type C6 sufficient animals. Here, the analysis of mesentery vascular expression of mRNA for vascular cell adhesion molecule (VCAM)-1, transforming growth factor$\beta$ (TGF- $\beta$ ), connective tissue growth factor (CTGF), and plateletderived growth factor (PDGF), the evaluation of intravascular protein levels of VCAM-1, TGF- $\beta$, CTGF, proliferative cell nuclear antigen (PCNA), as well as the assessment of structural changes and Complement components deposition at the mesentery arterial vascular wall were also performed.: Leukocyte trafficking, mesentery arteries hypertrophy, extracellular matrix deposition, local vascular gene and protein expression of VCAM- 1 , TGF- $\beta$, CTGF and PCNA, as well as PGDF gene expression were all increased by short term diabetes, but all significantly reduced in the $\mathrm{C} 6$ deficient diabetic animals, thus suggesting an active role for TCC in the development of vascular inflammation in the early phases of experimental diabetes.

Furthermore, recent studies have shown that hematopoietic bone marrow (BM) cells participate in the formation of different types of plaques, such as hyperlipidemia-induced atherosclerosis and transplant-associated vasculopathy $[170,171]$.

Excessive accumulation of smooth-muscle cells (SMCs) has a key role in the pathogenesis of vascular diseases. It has been assumed that SMCs derived from the outer medial layer migrate, proliferate and synthesize extracellular matrix components on the luminal side of the vessel. Although much effort has been devoted to targeting migration and proliferation of medial SMCs, there is no effective therapy that prevents occlusive vascular remodeling. We show here that in models of post-angioplasty restenosis, graft vasculopathy and hyperlipidemia-induced atherosclerosis, bone-marrow cells give rise to most of the SMCs that contribute to arterial remodeling. Notably, purified hematopoietic stem cells differentiate into SMCs in vitro and in vivo. Our findings indicate that somatic stem cells contribute to pathological remodeling of remote organs, and may provide the basis for the development of new therapeutic strategies for vascular diseases through targeting mobilization, homing, differentiation and proliferation of bone marrow-derived vascular progenitor cells.

Studies using chimeric animals revealed that bone marrow derived cells exist at the sites of vascular healing and lesion formation after injury. High-resolution histological analyses revealed that those bone marrow derived cells do express some markers for endothelial cells or smooth muscle cells. Peripheral mononuclear cells could differentiate into endothelial-like cells or smooth muscle like cells in vitro according to the culture conditions.

Circulating progenitors significantly contribute to vascular repair and lesion formation. These findings provide the basis for the development of new therapeutic strategies that involve targeting the mobilization, homing, differentiation, and proliferation of bone marrow- derived vascular progenitor cells.

In a study by Qiu et al. [171] authors attempted to use MRI to monitor, in vivo, trafficking of magnetically. labeled BM cells to atherosclerotic lesions BM-derived cells from LacZ-transgenic mice were labeled with a uperparamagnetic MR contrast agent, Feridex, and then transplanted into ApoE-/- recipient mice $(n=25)$ with an atherogenic diet for approximately 7-9 weeks. Histological examination revealed formations of atherosclerotic plaques in 17 cases and neointimal hyperplasia in 8 cases. Ex vivo high-resolution MR imaging demonstrated details of plaque structure, which was correlated with histology confirmation In Group I with Feridexlabeled BM cell transplantation, in vivo $\mathrm{MR}$ imaging showed larger MR signal voids of the aortic walls (due to the "blooming" effect of Feridex) in four cases, in which Feridex- and/or LacZ-positive cells 
were detected with histochemistry. No such findings were visualized in the two control animal groups. In the eight cases with intimal hyperplasia, no larger MR signal voids of the aortic walls were detected by in vivo MR imaging. In this study authors presented a potential method of using MRI to monitor, in vivo, trafficking of magnetically labeled bone marrow cells to atherosclerotic lesions, which may provide a useful tool to guide the targeting of hematopoietic cells for gene therapy- or chemotherapy-based interventions in atherosclerotic cardiovascular disease.

The mobilization and recruitment of bone marrow derived or resident progenitor cells giving rise to smooth muscle cells have been implicated in accelerated forms of primary plaque formation and neointimal hyperplasia after arterial injury. By contrast, convincing evidence has emerged that the arterial homing of endothelial progenitor cells contributes to endothelial recovery and thereby limits neointimal growth after endothelial denudation. In the chronic context of primary atherosclerosis, plaque progression and destabilization, a more complex picture has become apparent. Clinically, the number and function of endothelial progenitor cells have been linked with an improved endothelial function or regeneration and have been frequently inversely correlated with cardiovascular risk (factors). In animal models, however, the injection of bone marrow cells or endothelial progenitor cells, as well as the application of stem-cell mobilizing factors, have been associated with an exacerbation of atherosclerosis and unstable plaque phenotype, whereas the contribution of smooth muscle progenitors to primary atherosclerosis appears to be more confined to supporting plaque stability.Considering the balance between distinct circulating vascular progenitor cells and identifying mechanisms for selective control of their mobilization and homing appears crucial to improve prediction and to directly modulate endogenous vascular remodeling processes.

Recruitment of monocytes into atherogenic foci is required for the onset and progression of atherosclerosis. In lesions, monocytederived cells take up modified lipoprotein and produce secretory factors that attract and activate smooth muscle cells, other immune cells, and more monocytes. Mechanisms that attract monocytes to lesions are partly defined [172-174] but relatively little is known about the fate of monocytes once they migrate into lesions. Many begin to differentiate into lipid-laden macrophage foam cells, but it has also been recently appreciated that a substantial population of lesional foam cells in humans and animals bears features of dendritic cells (DCs), rather than macrophages.

Because tissue macrophage homeostasis is not maintained in atherosclerotic lesions, but instead macrophages accumulate abundantly in plaques along with cells resembling DCs, Liodrà et $a l$. examined herein whether the increase of monocyte-derived cells in atherosclerotic plaques might result not only from robust recruitment of monocytes into lesions, but also from a depressed rate of their migratory clearance from the lesions. Thus, we examined rates of emigration of human monocyte-derived cells out of a model of a vessel wall in the presence or absence of proatherogenic lipids and then compared migratory clearance of monocyte-derived cells from murine atherosclerotic lesions under conditions in which plaques regressed or progressed. these findings underscore a so-far unknown alteration in the cellular trafficking that distinguishes atherosclerotic lesions that regress compared with those that continue to progress and suggest that interventions to maintain functional pathways of emigration out of lesions may favor disease regression and quell plaque progression.

The presence of B cells in the adventitia of atherosclerotic arteries was described as early as 1981 [175], and CD22+ B cells were found in early fatty streak-type lesions and full-blown atherosclerotic plaques of apolipoprotein-E-defi cient (ApoE-/-) mice [176]. Although the impact of $\mathrm{B}$ cells on atherosclerosis development was not appreciated for a long time, recent studies show that B cell defi ciency increases atherosclerosis in LDL-receptor-/- (8) or
ApoE-/- mice [177]. The atheroprotective effect of B cells may be related to natural antibodies (Abs) produced by distinct sets of innate-like B cells, B1 cells, and marginal zone B cells [178].

Atherosclerosis is a chronic inflammatory disease of the arterial wall and an increasing body of evidence suggests that the immune system actively participates in the initiation, progression and persistence of atherosclerosis. Different types of leukocytes such as T and B lymphocytes, natural killer cells (NK) and NKT cells, macrophages, dendritic cells and mast cells have been found within atherosclerosis-prone aortas. The mechanisms of monocyte recruitment have been partially characterized and involve P-selectin, E-selectin, VCAM-1, ICAM-1 and JAM-A. CXCL1, CCL5, CXCL4, CXCL7 and MIF are also implicated in monocyte trafficking into aortas. Recently it has been reported that Ly6C(high) and Ly6C(low) monocyte subsets differently use CCL2, CX3CL1 and CCL5 for their homing into atherosclerotic aortas. $\mathrm{T}$ and $\mathrm{B}$ lymphocytes constitutively migrate into the normal and atherosclerotic aortic wall in an L-selectin-dependent manner. Recent studies suggest an important role of CCL5, CXCL10, CXCL16, CXCR6 and MIF in T cell influx into the atherosclerotic wall. However, there is little information available on the mechanisms of recruitment of other types of the immune cells such as NK, NKT and mast cells. In this review we shall summarize what is known about leukocyte recruitment into the aortic wall during atherosclerosis with a focus on mouse model systems.

Although numerous reports have described the involvement of different leukocyte types in atherosclerosis, few studies investigated the cell composition of the normal aorta $[179,180]$.

Galkina et al. [181] reported that $\mathrm{T}$ and $\mathrm{B}$ cells reside within the adventitia of normal/noninfl amed aortas as a consequence of constitutive homing that is partially L-selectin dependent. authors used a newly developed flow cytometry-based method to quantitatively investigate the alterations of immune cell composition that occurs during the development and progression of atherosclerosis in ApoE-/ mice, during which tertiary lymphoid tissue is formed in the adventitia of the aortas.

Flow cytometry of aortic cell suspensions showed that B and T lymphocytes and some macrophages and dendritic cells are already present in the adventitia of normal/noninflamed mouse aortas. Adoptively transferred lymphocytes constitutively homed to the aorta and resided within the adventitia up to $7 \mathrm{~d}$ after transfer. Lymphocyte trafficking into normal/noninflamed or atherosclerosis-prone aortas was partially L-selectin dependent. Antigenactivated dendritic cells induced increased $\mathrm{T}$ lymphocyte proliferation within the aorta $72 \mathrm{~h}$ after adoptive transfer. During progression of atherosclerosis in apolipoprotein-E-deficient mice, the total number of macrophages, T cells, and dendritic cells, but not B cells, increased significantly. This alteration in immune cell composition was accompanied by the formation of tertiary lymphoid tissue in the adventitia of atherosclerotic aortas. These results demonstrate that lymphocytes already reside within the normal/noninflamed aorta before the onset atherosclerosis as a consequence of constitutive trafficking. Atherosclerosis induces the recruitment of macrophages and dendritic cells that support antigen presentation.

Though substantial information is available on immune cells in atherosclerotic lesions of the lamina intima, cells in the lamina adventitia have received less attention. In a study by Moos et al. [182] The composition of immune cells in the innominate artery and abdominal aorta was examined in young, adult, and old apolipoprotein (apo) $\mathrm{E}(-/-)$ and wild-type mice on standard mouse chow. In the innominate artery of apoE(-/-) mice, adventitial $\mathrm{T}$ cells increased at 32,52 , and 78 weeks exceeding those of the intima by 6-, 24-, and 85 -fold. Single T cells dominated in young mice, later T/B cell clusters emerged, and lymphoid-like structures reminiscent of inflammatory follicles formed preferentially in the abdominal aorta of old mice. Follicles contained organized sets of immune response- 
regulating cells: Interdigitating dendritic cells, T cell effectors, proliferating B cells, and plasma cells. Adventitial T cell inflammation was associated with a marked increase in transcripts of the chemokine MIP-1alpha in the aorta but not in spleen or liver. Adventitial lymphocyte infiltration and formation of inflammatory follicle-like structures in the abdominal aorta of old apoE(-/-) mice point to the adventitia as a site of local adaptive immune reactions during atherogenesis in hyperlipidemic mice.

Recently, it has been shown that stem/progenitor cells may repair damaged/lost endothelial cells in vein grafts and wire-injured arteries. Recently some authors [183] investigated endothelial cell turnover and regeneration in apolipoprotein $\mathrm{E}$ (apoE)(-/-)/transgenic mice carrying LacZ genes driven by an endothelial TIE2 promoter. To assess cell proliferation on the surface of aortas in apoE(-/-) mice and wild-type controls, BrdU was injected into the tail vein and labeled on en face preparation. BrdU-positive cells on the aortas were observed occasionally in wild-type mice and frequently at sites prone to lesion development in apoE(-/-) mice $(0.18+/-0.1 \%$ versus $1.12+/-0.2 \% ; \mathrm{P}<0.001)$. Endothelial integrity tests demonstrated that the areas with high rate of cell turnover displayed Evans blue leakage, low levels of VE-cadherin expression, and increased cell attachment, as evidenced by Evans blue dye injection, immunostaining, and scanning electron microscopy, respectively. Furthermore, immunostaining for CD34, Sca-1, Flk-1, and CD133 indicated that approximately $3 \%$ to $5 \%$ of total cells on the aorta were positive in apoE(-/-) mice. En face double labeling using Ki67 and progenitor markers revealed that $30 \%$ to $50 \%$ of progenitor $(+)$ cells expressed $\mathrm{Ki}-67$, indicating a state of proliferation. To clarify the origin of endothelial progenitor cells participating in endothelial repair in apoE(-/-) mice, a chimeric mouse model was created by bone marrow transplantation between apoE(-/-) and $\mathrm{LacZ}(+/+) /$ apoE(-/-) mice. Ten months after bone marrow transplantation, approximately $3 \%$ to $4 \%$ of total cells in the lesionprone areas were beta-gal positive in apoE(-/-) with apoE(-/-)/TIE2LacZ bone marrow mice. When cells of aortas from chimeric mice were cultivated on Matrigel-coated plates, a capillary-like structure was found, which showed beta-gal/CD31 or beta-gal/von Willebrand factor double positivity. By a combined analysis of laser dissection microscopy and nest reverse transcription polymerase chain reaction, it was found that beta-gal $(+)$ cells were mainly expressing CD31 and CD144. These findings provide the first quantitative data on endothelial turnover and repair by progenitor cells that are, at least in part, derived from bone marrow during development of atherosclerosis in apoE(-/-) mice.

Moreover, Atherosclerosis is largely attributed to chronic vascular injury, as occurs with excess cholesterol; however, the effect of concomitant vascular aging remains unexplained. We hypothesize that the effect of time in atherosclerosis progression is related to obsolescence of endogenous progenitor cells that normally repair and rejuvenate the arteries.

Some authors [184] showed that chronic treatment with bone marrow-derived progenitor cells from young nonatherosclerotic ApoE-/-mice prevents atherosclerosis progression in ApoE-/- recipients despite persistent hypercholesterolemia. In contrast, treatment with bone marrow cells from older ApoE-/- mice with atherosclerosis is much less effective. Cells with vascular progenitor potential are decreased in the bone marrow of aging ApoE-/- mice, but cells injected from donor mice engraft on recipient arteries in areas at risk for atherosclerotic injury.These data indicate that progressive progenitor cell deficits may contribute to the development of atherosclerosis.

On this basis aging may the most powerful risk for the development of atherosclerosis and atherosclerotic thromboembolic complications. Yet, the mechanism by which aging affects the arterial wall and its deterioration has remained essentially uncharacterized. Chronic injuries to the arterial wall contribute to the development of atherosclerosis. However, it is important to note that a complex repair system that involves both local and bone marrowderived cells maintains arterial homeostasis and integrity. The agedependent failure of the bone marrow to produce vascular progenitor cells responsible for such arterial repair--an inability that results from the impact of a lifetime of risk factors such as hyperlipidemia-drives atherosclerosis and its thromboembolic complications. As a consequence of such failure, the normal processes of arterial wall repair and rejuvenation are impaired. The disequilibrium that ensues between injury of the arterial wall and repair leads to atherosclerotic inflammation and consequent thromboembolic complications. The bone marrow and derived progenitor cells represent key regulators of atherosclerosis, and progress in the prevention and treatment of atherosclerosis and its thromboembolic complications will need to take into account this new dimension for the disease process.

A novel concept [185] for atherosclerosis risk implicates a lack of endothelial progenitor cell (EPC)-dependent arterial repair in the development of the disease that is secondary to exhaustion of repair-competent EPCs. Molecular evidence derived from genetic techniques indicates atherosclerotic lesions may begin to form as arterial repair fails, rather than merely following arterial injury. Thus, chronic arterial injury may overwhelm the ability of EPCs to maintain arterial homeostasis, particularly when EPCs capable of arterial repair become exhausted. Recent studies have reported genes identified using non-biased approaches (ie, genetic linkage studies and genome-wide association studies) that are associated with susceptibility for atherosclerosis and related thromboembolic disorders; these genes may be implicated in the control of arterial wall inflammation and EPC-mediated tissue repair. Most of the genes identified by using non-biased genomic techniques are associated with inflammation, immune response and stem cells. This review focuses on new genetic data in the field of atherosclerosis and arterial homeostasis.

Recent studies of bone marrow (BM)-transplanted apoE knockout (apoE-/-) mice have concluded that a substantial fraction of smooth muscle cells (SMCs) in atherosclerosis arise from circulating progenitor cells of hematopoietic origin. This pathway, however, remains controversial. Bentzon et al. [186] reexamined the origin of plaque SMCs in apoE-/- mice by a series of BM transplantations and in a novel model of atherosclerosis induced in surgically transferred arterial segments. Authors analyzed plaques in lethally irradiated apoE-/- mice reconstituted with sex-mismatched BM cells from eGFP+ apoE-/- mice, which ubiquitously express enhanced green fluorescent protein (eGFP), but did not find a single SMC of donor BM origin among approximately 10,000 SMC profiles analyzed. We then transplanted arterial segments between eGFP+ apoE-/- and apoE-/- mice (isotransplantation except for the eGFP transgene) and induced atherosclerosis focally within the graft by a recently invented collar technique. No eGFP+ SMCs were found in plaques that developed in apoE-/- artery segments grafted into eGFP+ apoE-/- mice. Concordantly, 96\% of SMCs were eGFP + in plaques induced in eGFP + apoE-/- artery segments grafted into apoE-/- mice. These experiments show that SMCs in atherosclerotic plaques are exclusively derived from the local vessel wall in apoE-/- mice.

On this basis, antigen presentation may also occur within the atherosclerotic plaque (yellow on the right), which is rich in antigen presenting cells (APC: macrophages and dendritic cells). Continuous trafficking of immune cells between the inflamed atherosclerotic artery and the lymphoid organs may be necessary to mount an adaptive immune response.

\section{CONCLUSIONS}

Atherosclerosis is nowadays recognized as a chronic inflammatory disease of large arteries.

Atherosclerotic cardiovascular disease is the leading cause of death in industrialised countries and is quickly becoming the 
principal cause of death worldwide. For a long time, atherosclerosis was considered as a simple accumulation of lipids that would gradually obstruct the arteries leading to myocardial infarction and stroke. However, it was recently shown by many investigators including myself that atherosclerosis has an inflammatory basis. This discovery offers the opportunity to develop novel therapeutic strategies targeting the inflammatory component of the disease. This paradigm change was paralleled by the growing awareness that the majority of patients with rheumatoid arthritis and other inflammatory diseases die of premature cardiovascular diseases. The earliest changes in atherogenesis occur in the arterial endothelium. For reasons that are not entirely clear, the endothelium becomes more permeable to lipoproteins and immune system cells such as monocytes, $\mathrm{T}$ lymphocytes and leukocytes. The migration of these immune cells into arterial walls is mediated by oxidized low-density lipoprotein (LDL), cytokines and other blood factors. (Fatty streaks consisting of lipid- and cholesterol-rich monocytes, macrophages and $\mathrm{T}$ lymphocytes begin to form in arteries. This process is stimulated by the adherence and aggregation of platelets and by several mediators of the inflammatory response, including growth factors, cytokines such as interleukin-1 and tumor necrosis factor, and thrombaxane $A_{2}$ an eicosanoid derived from arachidonic acid. Refer to the table for a list of key inflammatory mediators.

With continued inflammation, the fatty streaks progress to advanced, complicated lipid-filled lesions. Eventually, a fibrous cap forms. Formation of the fibrous cap represents a healing response to the injury and is mediated by the actions of interleukin-1, tumor necrosis factor and other cytokines. When the advanced lesion becomes unstable, the plaque ruptures, causing a thrombosis that may result in myocardial infarction or stroke.

Several authors reported that when the mixed cell population contained within human atherosclerotic lesions is cultured in vitro, displays a dysregulated production of cytokines and chemokines in the absence of exogenous stimuli. Dyregulated inflammation in atherosclerotic plaques may be explained either by the persistence of pro-inflammatory stimuli or by the failure to resolve inflammation. Our research aims to characterise the molecular events of the dysregulated inflammation within the atherosclerotic plaques, and to identify strategies for its downregulation.

The use of biomarkers expressed by inflammatory cells, and especially circulating biomarkers, has gained a lot of attention because of their ability to reflect disease progression and predict the risk of a cardiovascular event. However, until now, no biomarkers, have been found that can detect high-risk patients with a good positive prognostic value. Therefore, novel sources of biomarkers are needed and one of the high-potential sources are circulating cells. Because macrophages play a crucial role in the development of atherosclerosis, a high focus has been placed on its precursor, the circulating monocyte. Recently it has become clear that the expression patterns of circulating monocytes changes in response to alterations in the diseased vessel wall, and multiple markers expressed by circulating monocytes have already been associated with disease progression like TLR, TNF $\alpha$ and IL-8. But more research and large trials are needed. With the circulating cell program of the CTMM project the expression of biomarkers on circulating monocytes and others cells will be investigated. Furthermore, a biosensor will be developed that is capable of measuring these biomarkers, so the development and progression of atherosclerotic disease and the identification of high-risk patients will be more accurate and easy to measure.

\section{CONFLICT OF INTEREST}

The authors confirm that this article content has no conflicts of interest.

\section{ACKNOWLEDGEMENT}

None declared.

\section{REFERENCES}

[1] Libby P, Theroux P. Pathophysiology of coronary artery disease. Circulation 2005; 111: 3481-8.

[2] Hansson GK, Libby P. The immune response in atherosclerosis: a double-edged sword. Nat Rev Immunol 2006; 6: 508 -19.

[3] Libby P, Ridker PM. Novel inflammatory markers of coronary risk: theory versus practice. Circulation 1999; 100: 1148 -50.

[4] Libby P, Ridker PM. Inflammation and atherosclerosis: role of Creactive protein in risk assessment. Am J Med 2004; 116 (Suppl 6A): 9S-16S.

[5] Ross R, Glomset JA. The pathogenesis of atherosclerosis. N Engl J Med 1976; 295: 369-77.

[6] Ross R. Atherosclerosis--an inflammatory disease. N Eng J Med 1999; 340(2): 115-26.

[7] Stary HC, Chandler AB, Glagov S, et al. A definition of initial, fatty streak, and intermediate lesions of atherosclerosis: a report from the Committee on Vascular Lesions of the Council on Arteriosclerosis, American Heart Association. Circulation 1994; 89: 2462-78.

[8] Charo IF, Ransohoff RM. The many roles of chemokines and chemokine receptors in inflammation. N Engl J Med 2006; 354 : 610-21.

[9] Weber C, Schober A, Zernecke A. Chemokines: key regulators of mononuclear cell recruitment in atherosclerotic vascular disease.Arterioscler Thromb Vasc Biol 2004; 24: 1997-2008.

[10] Ahn YT, Huang B, McPherson L, Clayberger C, Krensky AM. Dynamic interplay of transcriptional machinery and chromatin regulates "late" expression of the chemokine RANTES in T lymphocytes. Mol Cell Biol 2007; 27: 253-66.

[11] Krohn R, Raffetseder U, Bot I, et al. Y-box binding protein-1 controls CC chemokine ligand-5 (CCL5) expression in smooth muscle cells and contributes to neointima formation in atherosclerosisprone mice. Circulation 2007; 116: 1812-20.

[12] Cheng C, Tempel D, van Haperen R, et al. Shear stress-induced changes in atherosclerotic plaque composition are modulated by chemokines. J Clin Invest 2007; 117: 616-26.

[13] Schulz C, Schafer A, Stolla M, et al. Chemokine fractalkine mediates leukocyte recruitment to inflammatory endothelial cells in flowing whole blood: a critical role for P-selectin expressed on activated platelets. Circulation 2007; 116: 764 -73.

[14] Schreyer SA, Vick CM, LeBoeuf RC. Loss of lymphotoxin- alpha but not tumor necrosis factor-alpha reduces atherosclerosis in mice. J Biol Chem 2002; 277: 12364-8.

[15] Kirii H, Niwa T, Yamada Y, et al. Lack of interleukin-1beta decreases the severity of atherosclerosis in apoE-deficient mice. Arterioscler. Thromb Vasc Biol 2003; 23: 656-60

[16] Isoda K, Sawada S, Ishigami N, et al. Lack of interleukin-1 receptor antagonist modulates plaque composition in apolipoprotein Edeficient mice. Arterioscler Thromb Vasc Biol 2004; 24: 1068-73.

[17] Buono C, Come CE, Stavrakis G, Maguire GF, Connelly PW, Lichtman $\mathrm{AH}$. Influence of interferon-gamma on the extent and phenotype of diet-induced atherosclerosis in the LDLRdeficient mouse. Arterioscler Thromb Vasc Biol 2003; 23: 454-60.

[18] Boulay JL, O'Shea JJ, Paul WE. Molecular phylogeny within type I cytokines and their cognate receptors. Immunity 2003; 19: 15963.

[19] Balkwill FR, Burke F. The cytokine network. Immunol Today 1989; 10: 299-304.

[20] Nathan C. Points of control in inflammation. Nature 2002; 420 : 846-52.

[21] Pockley AG, Wu R, Lemne C, Kiessling R, de Faire U, Frostegard J. Circulating heat shock protein 60 is associated with early cardiovascular disease. Hypertension 2000; 36: 303-7.

[22] $\mathrm{Xu} \mathrm{Q}$, Schett G, Perschinka H, et al. Serum soluble heat shock protein 60 is elevated in subjects with atherosclerosis in a general population. Circulation 2000; 102: 14-20.

[23] Wright BH, Corton JM, El-Nahas AM, Wood RF, Pockley AG Elevated levels of circulating heat shock protein 70 (Hsp70) in peripheral and renal vascular disease. Heart Vessels 2000; 15: 18-22.

[24] Jonasson L, Holm J, Skalli O, Gabbiani G, Hansson GK. Expression of class II transplantation antigen on vascular smooth muscle cells in human atherosclerosis. J Clin Invest 1997; 76: 125-31.

[25] Frostegard J, Ulfgren AK, Nyberg P, et al. Cytokine expression in advanced human atherosclerotic plaques: dominance of pro- 
inflammatory (Th1) and macrophage-stimulating cytokines. Atherosclerosis $1999 ; 145: 33-43$.

[26] Hansson GK, Holm J, Jonasson L. Detection of activated T lymphocytes in the human atherosclerotic plaque. Am J Pathol 1989; 135: 169-75.

[27] Bureau MF, Soubrier F, Esposito B, et al. Protective role of interleukin-10 in atherosclerosis. Circ Res 1999; 85: e17-24.

[28] Pinderski Oslund LJ, Hedrick CC, Olvera T, et al. Interleukin-10 blocks atherosclerotic events in vitro and in vivo. Arterioscler Thromb Vasc Biol 1999; 19: 2847-53.

[29] Gojova A, Brun V, Esposito B, Cottrez F, et al. Specific abrogation of transforming growth factor-signaling in $\mathrm{T}$ cells alters atherosclerotic lesion size and composition in mice. Blood 2003; 102: 4052 8 .

[30] Grainger DJ, Mosedale DE, Metcalfe JC, Bottinger EP. Dietary fat and reduced levels of TGF 1 act synergistically to promote activation of the vascular endothelium and formation of lipid lesions. J Cell Sci 2000; 113: 2355-61.

[31] Lutgens E, Gijbels M, Smook M, et al. Transforming growth factor-beta mediates balance between inflammation and fibrosis during plaque progression. Arterioscler Thromb Vasc Biol 2002; 22: 975-82.

[32] Gojova A, Brun V, Esposito B, et al. Specific abrogation of transforming growth factor-_ signaling in $\mathrm{T}$ cells alters atherosclerotic lesion size and composition in mice. Blood 2003; 102: 4052-8.

[33] Grainger DJ, Mosedale DE, Metcalfe JC, Bottinger EP. Dietary fat and reduced levels of TGF 1 act synergistically to promote activation of the vascular endothelium and formation of lipid lesions. $\mathrm{J}$ Cell Sci 2000; 113: 2355-61.

[34] Lutgens E, Gijbels M, Smook M, et al. Transforming growth factor-beta mediates balance between inflammation and fibrosis during plaque progression. Arterioscler Thromb Vasc Biol 2002; 22: 975-82.

[35] Cohen T, Nahari D, Cerem LW, Neufeld G, Levi BZ. Interleukin 6 Induces the Expression of Vascular Endothelial Growth Factor. J Biol Chem 1996; 271: 736-41.

[36] Ikeda U, Ikeda M, Oohara T, Kano S, Yaginuma T. Mitogenic action of interleukin-1 alpha on vascular smooth muscle cells mediated by PDGF. Atherosclerosis 1990; 84(2-3): 183-8.

[37] Nomoto A, Mutoh S, Hagihara H, Yamaguchi I. Smooth muscle cell migration induced by inflammatory cell products and its inhibition by a potent calcium antagonist, nilvadipine.Atherosclerosis 1988; 72(2-3): 213-9.

[38] Muzio M, Stockwell BR, Stennicke HR, Salvesen GS, Dixit VM. An induced proximity model for caspase-8 activation. J Biol Chem 1998; 273(5): 2926-30.

[39] Madge LA, Pober JS. TNF signaling in vascular endothelial cells. Exp Mol Pathol 2001; 70(3): 317-25.

[40] Paria BC, Vogel SM, Ahmmed GU, et al. Tumor necrosis factoralpha-induced TRPC1 expression amplifies store-operated $\mathrm{Ca} 2+$ influx and endothelial permeability. Am J Physiol Lung Cell Mol Physiol 2004; 287(6): L1303-13.

[41] Mach F, Schönbeck U, Libby P.CD40 signaling in vascular cells: a key role in atherosclerosis?Atherosclerosis 1998; 137: S89-95.

[42] Noelle R. Immunity 19964, 415-419. 6. Van Cooten C, Banchereau JJ. Leukocyte Biol 2000; 67: 2-17.

[43] Fries K, Sempowski G, Gaspari A, Blieden T, Looney R, Phipps RP. Clin Immunol Immunopathol 1995; 77: 42-51.

[44] Smith RS, Smith TJ, Blieden TM, Phipps RP. Am J Pathol 1997; 151: 317-22.

[45] Mach F, Scho"nbeck U, Suhkova G, et al. Proc Natl Acad Sci USA 1997; 94: 1931-6.

[46] Mach F, Scho“nbeck U, Suhkova G, et al. Proc Natl Acad Sci USA 1997; 94: 931-6.

[47] Scho"nbeck U, Mach F, Sukhova G, et al. J Exp Med 1999; 89: 843-53.

[48] Mach F, Scho"nbeck U, Suhkova G, Bourcier T, Bonnefoy JY, Pober J, Libby P. Proc Natl Acad Sci 1997. Van Cooten C, Banchereau JJ. Leukocyte Biol 2000; 67: 2-17.

[49] Mach F, Scho"nbeck U, Sukhova G, Atkinson E, Libby P. Nature 1998 394, 200-203 19. Lutgens E, Gorelik L, Daemen M, De Muinck E, Grewal I, Koteliansky V, Flavell R. Nat. Med 1999; 5: 1313-6.

[50] Aukrust P, Muller F, Ueland T, et al. Circulation 1999; 100: 61420 .
[51] Schönbeck U, Sukhova GK, Shimizu K, Mach F, Libby P. Inhibition of CD40 signaling limits evolution of established atherosclerosis in mice. Proc Natl Acad Sci 2000; 20; 97(13): 7458-63.

[52] Mach F, Schönbeck U, Sukhova GK, Atkinson E, Libby P. Reduction of atherosclerosis in mice by inhibition of CD40 signalling. Nature 1998; 394(6689): 200-3

[53] Hansson GK. Inflammation, atherosclerosis, and coronary artery disease. N Engl J Med 2005; 352: 1685-95

[54] Tedgui A, Mallat Z. Cytokines in atherosclerosis: pathogenic and regulatory pathways. Physiol Rev 2006; 86: 515-81

[55] Hansson GK, Libby P, Schonbeck U, Yan ZQ. Innate and adaptive immunity in the pathogenesis of atherosclerosis. Circ Res 2002; 91: 281-91.

[56] Tedgui A, Mallat Z. Cytokines in atherosclerosis: pathogenic and regulatory pathways. Physiol Rev 2006; 86: 515-81.

[57] Belkaid Y. Regulatory T cells and infection: a dangerous necessity. Nat Rev Immunol 2007; 7: 875-88.

[58] Hansson GK, Libby P. The immune response in atherosclerosis: a double-edged sword. Nat Rev Immunol 2006; 6: 508-19.

[59] Ishibashi S, Goldstein JL, Brown MS, Herz J, Burns DK. Massive xanthomatosis and atherosclerosis in cholesterol-fed low density lipoprotein receptor-negative mice. J Clin Invest 1994; 93: 188593.

[60] Xu Q, Kleindienst R, Waitz W, Dietrich H, Wick G. Increased expression of heat shock protein 65 coincides with a population of infiltrating $\mathrm{T}$ lymphocytes in atherosclerotic lesions of rabbits specifically responding to heat shock protein 65 . J Clin Invest 1993; 91: 2693-702.

[61] Song L, Leung C, Schindler C. Lymphocytes are important in early atherosclerosis. J Clin Invest 2001; 108: 251-9.

[62] Zhou X, Nicoletti A, Elhage R, Hansson GK. Transfer of CD4(+) T cells aggravates atherosclerosis in immunodeficient apolipoprotein E knockout mice. Circulation 2000; 102: 2919-22.

[63] Mor A, Luboshits G, Planer D, Keren G, George J. Altered status of CD4(+)CD25(+) regulatory $\mathrm{T}$ cells in patients with acute coronary syndromes. Eur Heart J 2006; 27: 2530-7.

[64] Mallat Z, Gojova A, Brun V, et al. Induction of a regulatory $\mathrm{T}$ cell type 1 response reduces the development of atherosclerosis in apolipoprotein Eknockout mice. Circulation 2003; 108: 1232-7.

[65] Ait-Oufella H, Horvat B, Kerdiles Y, et al. Measles virus nucleoprotein induces a regulatory immune response and reduces atherosclerosis in mice. Circulation 2007; 116: 1707-13.

[66] Getz GS. The immune system in atherogenesis. J Lipid Res 2005; 46: $1-10$.

[67] Schönbeck U, Mach F, Sukhova GK, et al. Expression of stromelysin-3 in atherosclerotic lesions: regulation via CD40-CD40 ligand signaling in vitro and in vivo. J Exp Med 1999; 189(5): 843-53.

[68] Häkkinen T, Karkola K, Ylä-Herttuala S. Macrophages, smooth muscle cells, endothelial cells, and T-cells express CD40 and CD40L in fatty streaks and more advanced human atherosclerotic lesions. Colocalization with epitopes of oxidized low-density lipoprotein, scavenger receptor, and CD16 (Fc gammaRIII). Virchows Arch 2000; 437(4): 396-405.

[69] Merino A, Buendia P, Martin-Malo A, Aljama P, Ramirez R, Carracedo J. Senescent CD14+ CD16+ monocytes exhibit proinflammatory and proatherosclerotic activity. J Immunol 2011; 186(3): 1809-15.

[70] Geissmann F, Jung S, Littman DR. Blood monocytes consist of two principal subsets with distinct migratory properties. Immunity 2003; 19: 71-82.

[71] Geissmann F, et al. Blood monocytes: distinct subsets, how they relate to dendritic cells, and their possible roles in the regulation of T-cell responses. Immunol Cell Biol 2008; 86: 398-408.

[72] Tacke F, Randolph GJ. Migratory fate and differentiation of blood monocyte subsets. Immunobiology 2006; 211: 609-18.

[73] Varol C, Yona S, Jung S. Origins and tissue-context-dependent fates of blood monocytes. Immunol Cell Biol 2009; 87: 30-8.

[74] Imhof BA, Aurrand-Lions M. Adhesion mechanisms regulating the migration of monocytes. Nat Rev Immunol 2004; 4: 432-44; 15. Ley K, Laudanna C, Cybulsky MI, Nourshargh S. Getting to the site of inflammation: the leukocyte adhesion cascade updated. Nat Rev Immunol 2007; 7 : 678-89.

[75] Galkina E, Ley K. Immune and inflammatory mechanisms of atherosclerosis. Annu Rev Immunol 2009; 27: 165-97. 
[76] Llodra J, et al. Emigration of monocyte-derived cells from atherosclerotic lesions characterizes regressive, but not progressive, plaques. Proc Natl Acad Sci USA 2004; 101: 11779-84.

[77] Feig JE, Quick JS, Fisher EA. The role of a murine transplantation model of atherosclerosis regression in drug discovery. Curr Opin Investig Drugs 2009; 10: 232-8

[78] Randolph GJ. Emigration of monocyte-derived cells to lymph nodes during resolution of inflammation and its failure in atherosclerosis. Curr Opin Lipidol 2008; 19: 462-8.

[79] Gerrity RG, Naito HK, Richardson M, Schwartz CJ. Dietary induced atherogenesis in swine. Morphology of the intima in prelesion stages. Am J Pathol 1979; 95: 775-92.

[80] Napoli C, et al. Fatty streak formation occurs in human fetal aortas and is greatly enhanced by maternal hypercholesterolemia. Intimal accumulation of low density lipoprotein and its oxidation precede monocyte recruitment into early atherosclerotic lesions. J Clin Invest 1997; 100: 2680-90.

[81] Ylitalo R, Oksala O, Yla-Herttuala S, Ylitalo P. Effects of clodronate (dichloromethylene bisphosphonate) on the development of experimental atherosclerosis in rabbits. J Lab Clin Med 1994; 123: $769-76$.

[82] Hunt KJ, Pankow JS, Offenbacher S, et al. B-mode ultrasounddetected carotid artery lesions with and without acoustic shadowing and their association with markers of inflammation and endothelial activation: the atherosclerosis risk in communities study. Atherosclerosis 2002; 162: 145-55.

[83] Østerud B, Bjørklid E. Role of monocytes in atherogenesis. Physiol Rev 2003; 83: 1069 -1112.

[84] Van DM, I, De Maat MP, Bots ML, et al. Inflammatory mediators and cell adhesion molecules as indicators of severity of atherosclerosis: the Rotterdam Study. Arterioscler Thromb Vasc Biol 2002; 22: 838-42.

[85] Hwang SJ, Ballantyne CM, Sharrett AR, et al. Circulating adhesion molecules VCAM-1, ICAM-1, and E-selectin in carotid atherosclerosis and incident coronary heart disease cases: the Atherosclerosis Risk In Communities (ARIC) study. Circulation 1997; 96: 4219-25.

[86] Chapman CM, Beilby JP, McQuillan BM, Thompson PL, Hung J. Monocyte count, but not C-reactive protein or interleukin-6, is an independent risk marker for subclinical carotid atherosclerosis. Stroke 2004; 35: 1619 -24.

[87] Mastronardi ML, Mostefai HA, Soleti R, Agouni A, Martínez MC, Andriantsitohaina R. Microparticles from apoptotic monocytes enhance nitrosative stress in human endothelial cells Fundam Clin Pharmacol 2011; 25(6): 653-60.

[88] Seibert E, Heine GH, Fliser D, Girndt M. Monocyte Angiotensin Converting Enzyme Expression May Be Associated with Atherosclerosis Rather than Arteriosclerosis in Hemodialysis Patients. Clin J Am Soc Nephrol 2011; 6(3): 505-11.

[89] Bielinski SJ, Hall JL, Pankow JS, Boerwinkle E, Matijevic-Aleksic $\mathrm{N}, \mathrm{He} \mathrm{M}$. Genetic variants in TLR2 and TLR4 are associated with markers of monocyte activation: the Atherosclerosis Risk in Communities MRI Study.Chambless L, Folsom AR. Hum Genet 2011; 129(6): 655-62

[90] Yassin LM,Londoño J, Montoya G, et al. Atherosclerosis development in SLE patients is not determined by monocytes ability to bind/endocytose Ox-LDL. Autoimmunity 2011; 44(3): 201-10.

[91] Rautou PE, Leroyer AS, Ramkhelawon B, et al. Circ Res 2011; 108(3): 335-43.

[92] von zur Muhlen C, Fink-Petri A, Salaklang J, et al. Imaging monocytes with iron oxide nanoparticles targeted towards the monocyte integrin MAC-1 (CD11b/CD18) does not result in improved atherosclerotic plaque detection by in vivo MRI. Contrast Media Mol Imaging 2010; 5(5): 268-75.

[93] Boyle JJ. Macrophage activation in atherosclerosis: pathogenesis and pharmacology of plaque rupture. Curr Vasc Pharmacol 2005; 3(1): 63-8.

[94] Schroecksnadel K, Frick B, Winkler C, Fuchs D. Crucial role of interferon-gamma and stimulated macrophages in cardiovascular disease. Curr Vasc Pharmacol 2006; 4(3): 205-13.

[95] Tiwari RL, Singh V, Barthwal MK. Macrophages: an elusive yet emerging therapeutic target of atherosclerosis. Med Res Rev 2008; 28(4): 483-544.

[96] Linton MF, Fazio S. Macrophages, inflammation, and atherosclerosis. Int J Obes Relat Metab Disord. 2003; 27 (Suppl 3): S35-40.

[97] Boisvert WA, Santiago R, Curtiss LK, Terkeltaub RA. A leukocyte homologue of the IL-8 receptor CXCR-2 mediates the accumula- tion of macrophages in atherosclerotic lesions of LDL receptordeficient mice. J Clin Invest 1998, 101: 353-63.

[98] Boring L, Gosling J, Cleary M, Charo IF. Decreased lesion formation in CCR2 / mice reveals a role for chemokines in the initiation of atherosclerosis. Nature 1998; 394: 894-7.

[99] Combadiere C, Potteaux S, Gao JL, et al. Decreased atherosclerotic lesion formation in CX3CR1/apolipoprotein E double knockout mice. Circulation 2003; 107: 1009-101.

[100] Gosling J, Slaymaker S, Gu L, et al. MCP-1 deficiency reduces susceptibility to atherosclerosis in mice that overexpress human apolipoprotein B. J Clin Invest 1999; 103: 773-8.

[101] Lesnik P, Haskell CA, Charo IF. Decreased atherosclerosis in CX3CR1-/-mice reveals a role for fractalkine in atherogenesis. J Clin Invest 2003; 111: 333-40.

[102] McDermott DH, Fong AM, Yang Q, et al. Chemokine receptor mutant CX3CR1-M280 has impaired adhesive function and correlates with protection from cardiovascular disease in humans. J Clin Invest 2003; 111: 1241-50.

[103] Barlic J, Zhang Y, Foley JF, Murphy PM. Oxidized lipid-driven chemokine receptor switch, CCR2 to CX3CR1, mediates adhesion of human macrophages to coronary artery smooth muscle cells through a peroxisome proliferator-activated receptor gammadependent pathway. Circulation 2006; 22; 114(8): 807-19.

[104] Springer TA, Cybulsky MI. Traffic signals on endothelium for leukocytes in health, inflammation, and atherosclerosis. In: Fuster V, Ross R, Topol EJ, Eds. Atherosclerosis and coronary artery disease. Vol. 1. Philadelphia: Lippincott- Raven, 1996; pp. 511-38.

[105] Muller WA, Weigl SA, Deng X, Phillips DM. PECAM-1 is requie for transendothelial

[106] Giachelli CM, Lombardi D, Johnson RJ, Murry CE, Almeida M. Evidence for a role of osteopontin in macrophage infiltration in response to pathological stimuli in vivo. Am J Pathol 1998; 152: $353-$ 8.

[107] McEver RP, Moore KL, Cummings RD. Leukocyte trafficking mediated by selectin-carbohydrate interactions. J Biol Chem 1995; 270: 11025-8.

[108] Ley K, Kansas GS. Selectins in T-cell recruitment to non-lymphoid tissues and sites of inflammation. Nat Rev Immunol 2004; 4: 325 35 .

[109] van der Wal AC, Das PK, Tigges AJ, Becker AE. Adhesion molecules on the endothelium and mononuclear cells in human atherosclerotic lesions. Am J Pathol 1992; 141: 1427-33.

[110] Collins RG, Velji R, Guevara NV, et al. P-Selectin or intercellular adhesion molecule (ICAM)-1 deficiency substantially protects against atherosclerosis in apolipoprotein Edeficient mice. J Exp Med 2000; 191: 189-94

[111] Weyrich AS, McIntyre TM, McEver RP, Prescott SM, Zimmerman GA. Monocyte tethering by P-selectin regulates monocyte chemotactic protein-1 and tumor necrosis factor-alpha secretion. Signal integration and NF-kappa B translocation. J Clin Invest 1995; 95: 2297-303.

[112] Luo BH, Carman CV, Springer TA. Structural basis of integrin regulation and signaling. Annu Rev Immunol 2007; 25: 619-47.

[113] World CJ, Garin G, Berk B. Vascular shear stress and activation of inflammatory genes. Curr Atheroscler Rep 2006; 8: 240-4.

[114] Zand T, Hoffman AH, Savilonis BJ, et al. Lipid deposition in rat aortas with intraluminal hemispherical plug stenosis. A morphological and biophysical study. Am J Pathol 1999; 155: 85-92.

[115] Huo Y, Weber C, Forlow SB, et al. The chemokine KC, but not monocyte chemoattractant protein-1, triggers monocyte arrest on early atherosclerotic endothelium. J Clin Invest 2001; 108: 130714.

[116] von Hundelshausen P, Koenen RR, Sack M, et al. Heterophilic interactions of platelet factor 4 and RANTES promote monocyte arrest on endothelium. Blood 2005; 105: 924-30.

[117] Rivera-Nieves J, Burcin TL, Olson TS, et al. Critical role of endothelial P-selectin glycoprotein ligand 1 in chronic murine ileitis. J Exp Med 2006; 203: 907-17.

[118] Huo Y, Hafezi-Moghadam A, Ley K. Role of vascular cell adhesion molecule-1 and fibronectin connecting segment-1 in monocyte rolling and adhesion on early atherosclerotic lesions. Circ Res 2000; 87: 153-9.

[119] Burger PC, Wagner DD. Platelet P-selectin facilitates atherosclerotic lesion development. Blood 2003; 101: 2661-6. 
[120] Tsou JK, Gower RM, Ting HJ, et al. Spatial regulation of inflammation by human aortic endothelial cells in a linear gradient of shear stress. Microcirculation 2008; 15(4): 311-23

[121] Gawaz M. Role of platelets in coronary thrombosis and reperfusion of ischemic myocardium. Cardiovasc Res 2004; 61: 498-511.

[122] Hawrylowicz CM, Howells GL, Feldmann M. Platelet-derived interleukin 1 induces human endothelial adhesion molecule expression and cytokine production. J Exp Med 1991; 174: 785-90.

[123] Kaplanski G. et al. Interleukin-1 induces interleukin-8 secretion from endothelial cells by a juxtacrine mechanism. Blood 1994. 84: 4242-8.

[124] Boring L, Gosling, J, Cleary M, Charo IF. Decreased lesion formation in CCR2-/- mice reveals a role for chemokines in the initiation of atherosclerosis. Nature 1998; 394: 894-7.

[125] Lu B, Rutledge BJ, Gu L, et al. Abnormalities in monocyte recruitment and cytokine expression in monocyte chemoattractant protein 1-deficient mice. J Exp Med 1998; 187: 601-8.

[126] Weber C. Platelets and chemokines in atherosclerosis: partners in crime. Circ Res 2005; 96: 612-6.

[127] von Hundelshausen P, Weber KS, Huo Y, et al. RANTES deposition by platelets triggers monocyte arrest on inflamed and atherosclerotic endothelium. Circulation 2001; 103: 1772-7.

[128] Schober A, Manka D, von Hundelshausen P, et al. Deposition of platelet RANTES triggering monocyte recruitment requires $\mathrm{P}$ selectin and is involved in neointima formation after arterial injury. Circulation 2002; 106: 1523-9.

[129] Scheuerer B, Ernst M, Dürrbaum-Landmann I, et al. The CXCchemokine platelet factor 4 promotes monocyte survival and induces monocyte differentiation into macrophages. Blood 2000; 95 : 1158-66.

[130] Sachais BS, Kuo A, Nassar T, et al. Platelet factor 4 binds to lowdensity lipoprotein receptors and disrupts the endocytic machinery, resulting in retention of low-density lipoprotein on the cell surface. Blood 2002; 99: 3613-22.

[131] Nassar T, Sachais BS, Akkawi S, et al. Platelet factor 4 enhances the binding of oxidized low-density lipoprotein to vascular wall cells. J Biol Chem 2003; 278: 6187-93.

[132] Massberg S, Brand K, Grüner S, et al. A critical role of platelet adhesion in the initiation of atherosclerotic lesion formation. J Exp Med 2002; 196: 887-96.

[133] Theilmeier G, Michiels C, Spaepen E, et al. Endothelial von Willebrand factor recruits platelets to atherosclerosisprone sites in response to hypercholesterolemia. Blood 2002; 99: 4486-93.

[134] Massberg S, Brand K, Grüner S, et al. A critical role of platelet adhesion in the initiation of atherosclerotic lesion formation. J Exp Med 2002; 196: 887-96.

[135] Massberg S, Schürzinger K, Lorenz M, et al. Platelet adhesion via glycoprotein IIb integrin is critical for atheroprogression and focal cerebral ischemia: an in vivo study in mice lacking glycoprotein IIb. Circulation 2005; 12: 1180-8.

[136] Huo Y, Schober A, Forlow SB, et al. Circulating activated platelets exacerbate atherosclerosis in mice deficient in apolipoprotein $\mathrm{E}$. Nat Med 2003; 9: 61-7.

[137] Dong ZM, Chapman SM, Brown AA, Frenette PS, Hynes RO, Wagner DD. The combined role of P- and E-selectins in atherosclerosis. J Clin Invest 1998; 102: 145-152. 75.

[138] Dong ZM, Brown AA, Wagner DD. Prominent role of P-selectin in the development of advanced atherosclerosis in ApoE-deficient mice. Circulation 2000; 101: 2290-5.

[139] Burger PC, Wagner DD. Platelet P-selectin facilitates atherosclerotic lesion development. Blood 2003; 101: 2661-6.

[140] Belton OA, Duffy A, Toomey S, Fitzgerald DJ. Cyclooxygenase isoforms and platelet vessel wall interactions in the apolipoprotein E knockout mouse model of atherosclerosis. Circulation 2003; 08: 3017-23.

[141] Lutgens E, Gorelik L, Daemen MJ, et al. Requirement for CD154 in the progression of atherosclerosis. Nat Med 1999; 5: 1313-6.

[142] Schonbeck U, Sukhova GK, Shimizu K, Mach F, Libby P. Inhibition of CD40 signaling limits evolution of established atherosclerosis in mice. Proc Natl Acad Sci USA 2000; 97: 7458-63.

[143] Mach F, Schonbeck U, Sukhova GK, Atkinson E, Libby P. Reduction of atherosclerosis in mice by inhibition of CD40 signalling. Nature 1998; 94: 200-3.

[144] Willoughby S, Holmes A, Loscalzo J. Platelets and cardiovascular disease. Eur J Cardiovasc Nurs 2002; 273-88.
[145] Fateh-Moghadam S, Bocksch W, Ruf A, et al. Changes in surface expression of platelet membrane glycoproteins and progression of heart transplant vasculopathy. Circulation 2000; 102: 890-7.

[146] Fateh-Moghadam S, Li Z, Ersel S, et al. Platelet degranulation is associated with progression of intimamedia thickness of the common carotid artery in patients with diabetes mellitus type 2 . Arterioscler. Thromb Vasc Biol 2005; 25: 1299-303.

[147] Koyama H, Maeno T, Fukumoto S, et al. Platelet P-selectin expression is associated with atherosclerotic wall thickness in carotid artery in humans. Circulation 2003; 108: 524-9.

[148] Gawaz M, Stellos K, Langer HF. Platelets modulate atherogenesis and progression of atherosclerotic plaques via interaction with progenitor and dendritic cells. J Thromb Haemost 2008; 6(2): 235-42.

[149] Daub K, Langer H, Seizer P, et al. Platelets induce differentiation of human CD34+ progenitor cells into foam cells and endothelial cells. FASEB J 2006; 20(14): 2559-61.

[150] Song YG, Kwon HM, Kim JM, et al. Serologic and histopathologic study of Chlamydia pneumoniae infection in atherosclerosis: a possible pathogenetic mechanism of atherosclerosis induced by Chlamydia pneumoniae. Yonsei Med J 2000; 41(3): 319-27.

[151] Blasi F, Denti F, Erba M, et al. Detection of Chlamydia pneumoniae but not Helicobacter pylori in atherosclerotic plaques of aortic aneurysms J Clin Microbiol 1996; 34(11): 2766-9.

[152] Mayr M, Kiechl S, Willeit J, Wick G, Xu Q. Infections, immunity, and atherosclerosis: associations of antibodies to Chlamydia pneumoniae, Helicobacter pylori, and cytomegalovirus with immune reactions to heat-shock protein 60 and carotid or femoral atherosclerosis. Circulation 2000; 102(8): 833-9.

[153] Liao D, Myers R, Hunt S, et al. Familial history of stroke and stroke risk. The Family Heart Study. Stroke 1997; 28: 1908-12.

[154] Kiely DK, Wolf PA, Coupples LA, Beiser AS, Myers RH. Familial aggregation of stroke. The Framingham Study. Stroke 1993; 24: 1366-71.

[155] Tjernstrom F, Hellmer G, Nived O, Truedsson L, Sturfelt G. Synergetic effect between interleukin-1 receptor antagonist allele (IL1RN*2) and MHC class II (DR17, DQ2) in determining susceptibility to systemic lupus erythematosus. Lupus 1999; 8: 103-8.

[156] Schrijver HM, Crusius JB, Uitdehaag BM, et al. Association of interleukin-1beta and interleukin-1 receptor antagonist genes with disease severity in MS. Neurology 1999; 52: 595-9.

[157] Bioque G, Crusius JB, Koutroubakis I, et al. Allelic polymorphism in IL-1 beta and IL-1 receptor antagonist (IL-1Ra) genes in inflammatory bowel disease. Clin Exp Immunol 1995; 102: 379-83.

[158] Ridker PM. On evolutionary biology, inflammation, infection, and the causes of atherosclerosis. Circulation 2002; 105: 2- 4.

[159] Fernandez-Real RJM, Ricart W. Insulin resistance and inflammation in an evolutionary perspective: the contribution of cytokine genotype/phenotype to thriftiness. Diabetologia 1999; 42: 1367-74.

[160] Jonsdottir S, Gudmundsdottir T, Bjarnadottir T, et al. The gene encoding phosphodiesterase 4D confers risk of ischemic stroke. Nat Genet 2003; 35: 131-8.

[161] Worrall BB, Azhar S, Nyquist PA, Ackerman RH, Hamm TL, DeGraba TJ. Interleukin-1 receptor antagonist gene polymorphisms in carotid atherosclerosis. Stroke 2003; 34: 790 -3.

[162] Ameziane N, Beillat T, Verpillat P, et al. Association of the Tolllike receptor-4 gene Asp299Gly polymorphism with acute coronary events. Arterioscler Thromb Vasc Biol 2003; 23: 61e-4e.

[163] Jerrard-Dunne P, Sitzer M, Risley P, Buehler A, von Kegler S, Markus HS. Inflammatory gene load is associated with enhanced inflammation and early carotid atherosclerosis in smokers Stroke 2004; 35(11): 2438-43.

[164] Markus HS, Labrum R, Bevan S, et al. Genetic and acquired inflammatory conditions are synergistically associated with early carotid atherosclerosis. Stroke 2006; 37(9): 2253-9.

[165] Thomas MC, Pickering RJ, Tsorotes D, et al. Genetic Ace2 deficiency accentuates vascular inflammation and atherosclerosis in the ApoE knockout mouse. Circ Res 2010; 107(7): 888-97.

[166] Minear MA, Crosslin DR, Sutton BS, et al. Polymorphic variants in tenascin-C (TNC) are associated with atherosclerosis and coronary artery disease. Hum Genet 2011; 129(6): 641-54.

[167] Babinska A, Azari BM, Salifu MO, et al. The F11 receptor (F11R/JAM-A) in atherothrombosis: overexpression of F11R in atherosclerotic plaques. Thromb Haemost 2007; 97(2): 272-81.

[168] Azari BM, Marmur JD, Salifu MO, et al. Silencing of the F11R gene reveals a role for F11R/JAM-A in the migration of inflamed 
vascular smooth muscle cells and in atherosclerosis. Atherosclerosis 2010; 212(1): 197-205.

[169] Wang KD, Liu ZZ, Wang RM, et al. Chemokine CXC Ligand 16 serum concentration but not A181V genotype is associated with atherosclerotic stroke. Clin Chim Acta 2010; 411(19-20): 1447-51.

[170] Fischetti F, Candido R, Toffoli B, et al. Innate immunity, through late complement components activation, contributes to the development of early vascular inflammation and morphologic alterations in experimental diabetes. Atherosclerosis 2011;216(1): 83-9.

[171] Sata M, Saiura A, Kunisato A, et al. Hematopoietic stem cells differentiate into vascular cells that participate in the pathogenesis of atherosclerosis. Nat Med 2002; 8(4): 403-9.

[172] Qiu1 B, Walczak P, Zhang J, et al. Proc In vivo MR Imaging of Bone Marrow Cell Trafficking to Atherosclerotic Plaques. Int Soc Mag Reson Med 14 (2006)

[173] Glass CK, Witztum JL. Atherosclerosis the road ahead Cell 2001; 104: 503-16.

[174] Osterud B, Bjorklid E. Role of monocytes in atherogenesis. Physiol Rev 2003; 83(4): 1069-112.

[175] Llodrá J, Angeli V, Liu J, Trogan E, Fisher EA, Randolph GJ. Emigration of monocyte-derived cells from atherosclerotic lesions characterizes regressive, but not progressive, plaques. Proc Natl Acad Sci USA 2004; 101(32): 11779-84.

[176] Parums D, Mitchinson MJ. Demonstration of immunoglobulin in the neighbourhood of advanced atherosclerotic plaques. Atherosclerosis 1981; 38: 211-6.

[177] Zhou X, Hansson GK. Detection of B cells and proinfl amatory cytokines in atherosclerotic plaques of hypercholesterolaemic apolipoprotein E knockout mice. Scand J Immun 1999; 50: 25-30.

[178] Caligiuri GA, Nicoletti B, Poirier GK. Hansson. Protective immunity against atherosclerosis carried by $\mathrm{B}$ cells of hypercholesterolemic mice. J Clin Invest 2002; 109: 745-53.
[179] Binder CJ, Silverman GJ. Natural antibodies and the autoimmunità of atherosclerosis. Springer Semin Immunopathol 2005; 385-404.

[180] Wick GM, Romen A, Amberger B, Metzler M, Mayr G, Falkensammer QXu. Atherosclerosis, autoimmunity, and vascularassociated lymphoid tissue. FASEB J 1997; 11: 1199-207.

[181] Tavian ML, Coulombel D, Luton HS, Clemente F. DieterlenLievre, B. Peault.Aorta-associated CD34+ hematopoietic cells in the early human embryo. Blood 1996; 87: 67-72.

[182] Galkina E, Kadl A, Sanders J, Varughese D, Sarembock IJ, Ley K. Lymphocyte recruitment into the aortic wall before and during development of atherosclerosis is partially L-selectin dependent. J Exp Med 2006; 203(5): 1273-82.

[183] Moos MP, John N, Gräbner R, et al. The lamina adventitia is the major site of immune cell accumulation in standard chow-fed apolipoprotein E-deficient mice. Arterioscler Thromb Vasc Biol 2005; 25(11): 2386-91

[184] Foteinos G, Hu Y, Xiao Q, Metzler B, Xu Q. Rapid endothelial turnover in atherosclerosis-prone areas coincides with stem cell repair in apolipoprotein E-deficient mice. Circulation 2008; 117(14): 1856-63.

[185] Rauscher FM, Goldschmidt-Clermont PJ, Davis BH, et al. Aging, progenitor cell exhaustion, and atherosclerosis. Circulation 2003 108(4): 457-63.

[186] Goldschmidt-Clermont PJ, Seo DM, Wang L, et al. Inflammation, stem cells and atherosclerosis genetics. Curr Opin Mol Ther 2010; 12(6): 712-23.

[187] Bentzon JF, Weile C, Sondergaard CS, Hindkjaer J, Kassem M, Falk E. Smooth muscle cells in atherosclerosis originate from the local vessel wall and not circulating progenitor cells in ApoE knockout mice. Arterioscler Thromb Vasc Biol 2006; 26(12): 2696-702. 